\title{
Impact of South Pacific Subtropical Dipole Mode on the Equatorial Pacific ${ }^{\mathscr{O}}$
}

\author{
JIAN ZHENG \\ Key Laboratory of Ocean Circulation and Waves, Institute of Oceanology, Chinese Academy of Sciences, and \\ Laboratory for Ocean and Climate Dynamics, Qingdao National Laboratory for Marine Science and \\ Technology, Qingdao, China \\ FAMING WANG \\ Key Laboratory of Ocean Circulation and Waves, Institute of Oceanology, Chinese Academy of Sciences, and \\ Laboratory for Ocean and Climate Dynamics, Qingdao National Laboratory for Marine Science and \\ Technology, Qingdao, and University of Chinese Academy of Sciences, Beijing, China \\ Michael A. AleXANDER \\ NOAA/Earth System Research Laboratory, Boulder, Colorado \\ MENGYANG WANG \\ Key Laboratory of Ocean Circulation and Waves, Institute of Oceanology, Chinese Academy of Sciences, \\ Qingdao, and University of Chinese Academy of Sciences, Beijing, China
}

(Manuscript received 18 April 2017, in final form 26 November 2017)

\begin{abstract}
Previous studies have indicated that a sea surface temperature anomaly (SSTA) dipole in the subtropical South Pacific (SPSD), which peaks in austral summer (January-March), is dominated by thermodynamic processes. Observational analyses and numerical experiments were used to investigate the influence of SPSD mode on the equatorial Pacific. The model is an atmospheric general circulation model coupled to a reducedgravity ocean model. An SPSD-like SSTA was imposed on 1 March, after which the model was free to evolve until the end of the year. The coupled model response showed that warm SSTAs extend toward the equator with northwesterly wind anomalies and then grow to El Niño-like anomalies by the end of the year. SPSD forcing weakens southeasterly trade winds and propagates warm SSTAs toward the equator through windevaporation-SST (WES) feedback. Meanwhile, relaxation of trade winds in the eastern equatorial Pacific depresses the thermocline and upwelling. Eastward anomalous currents near the equator cause warm horizontal advection in the central Pacific. Further experiments showed that thermodynamic coupling mainly acts on but is not essential for SSTA propagation, either from the subtropics to the equator or westward along the equator, while oceanic dynamic coupling alone also appears to be able to initiate anomalies on the equator and plays a critical role in SSTA growth in the tropical Pacific. This is consistent with observational analyses, which indicated that influence of WES feedback on SSTA propagation associated with the SPSD is limited. Finally, the warm pole close to the equator plays the dominant role in inducing the El Niño-like anomalies.
\end{abstract}

\section{Introduction}

El Niño-Southern Oscillation (ENSO), which occurs in the tropical Pacific, is the strongest interannual climate variation in the global climate system. ENSO is

Supplemental information related to this paper is available at the Journals Online website: https://doi.org/10.1175/JCLI-D-17-0256.s1.

Corresponding author: Jian Zheng, zhengjian@qdio.ac.cn thought to impact mid-to-high-latitude climate variability through an atmospheric bridge (e.g., Alexander et al. 2002); however, variability in mid-to-high latitudes could potentially influence ENSO through both oceanic and atmospheric processes. Many studies have considered North Pacific air-sea coupled variability and have shown that the North Pacific Oscillation (NPO; Rogers 1981; Linkin and Nigam 2008), the second leading mode of atmospheric variability during boreal winter, can trigger ENSO-like variability in the following winter 
(Vimont et al. 2001, 2003a,b, 2009; Alexander et al. 2010). The southern part of the NPO can induce an anomalous sea surface temperature (SST) "footprint" in the subtropical North Pacific via changes to northeast trade winds and thereby the surface heat fluxes. The SST footprint interacts with the trade winds and persists throughout summer in the subtropics. The subtropical SST anomalies (SSTAs) propagate southwest toward the equator under the feedback between the surface wind, evaporation, and SSTA (WES feedback). These coupling processes extend to the western and central equatorial Pacific through wind stresses and SST anomalies and can trigger a winter ENSO event via oceanic dynamic processes. This process, which is known as the seasonal footprinting mechanism (SFM), has been diagnosed from observations (Vimont et al. 2003b), coupled general circulation model simulations (Vimont et al. 2001, 2003a), and numerical model experiments (Vimont et al. 2009; Alexander et al. 2010). Meanwhile, these SSTAs can also modify the tropical SST meridional gradient across the mean latitude of the intertropical convergence zone (ITCZ) and displace the ITCZ toward the warm water. This phenomenon, termed the North Pacific meridional mode (NPMM; Chiang and Vimont 2004), has been shown to be a thermodynamic coupled mode independent of ENSO. It is argued that the NPMM effectively serves as a conduit through which the extratropical atmosphere influences ENSO. Both observations and model simulations show that most El Niño events are preceded by an NPMM event (Chang et al. 2007; Zhang et al. 2009) and that the NPMM plays a fundamental role in the seasonal phaselocking behavior of ENSO (Chang et al. 2007).

Air-sea coupled variability in the South Pacific (SP) also exerts an influence on the tropical Pacific. Some studies have already linked the undeveloped El Niño of 2014 to negative SSTAs in the southeastern Pacific during early 2014 (Min et al. 2015; Zhu et al. 2016), in which wind anomalies over the eastern equatorial $\mathrm{Pa}$ cific caused by the negative SSTAs hindered growth of the warm SSTA into El Niño after the summer of 2014. Recently, a meridional mode was also identified in the South Pacific (SPMM; Zhang et al. 2014a). The SPMM is generated by changes in surface latent heat flux modulated by off-equatorial southeast trade winds, a mechanism that is nearly identical to that of NPMM. The SPMM has also been found to lead to ENSO-like variability in a slab ocean model (Zhang et al. 2014a; Clement et al. 2011). WES feedback is strongest when anomalous winds and mean wind are in opposite directions. The equatorward propagation of SSTAs of meridional modes does not go beyond the location of the convergence zone of mean northeasterly trades and mean southeasterly trades. With the mean ITCZ located north of the equator in the eastern Pacific and southeasterly trade winds extending across the equator, the SPMM has a stronger expression in the equatorial Pacific than the NPMM (Zhang et al. 2014b). Statistical analyses suggests that the Pacific-South American (PSA) pattern could induce an SSTA footprint in the South Pacific, leading to zonal wind anomalies in the equatorial Pacific that ultimately trigger a winter ENSO event (Ding et al. 2015).

Some of the above studies did not consider that ENSO also influences the atmospheric circulation, despite that the PSA pattern can be regarded as a tropicalextratropical teleconnection triggered by convective heating related to ENSO (e.g., Mo and Paegle 2001). Wang (2010a) showed that the leading mode of SSTA variability in the SP after removing the ENSO signal is a dipole pattern in the southeastern subtropical Pacific. As shown in Fig. 1, the dipole SSTA pattern is associated with trade wind anomalies in the tropics and may interact with the westerlies in midlatitudes. Its formation mainly reflects wind-induced latent heat flux (LHF) changes and cloud-induced solar radiation changes (Zheng and Wang 2017). This coupled mode arises in the analytical solution of a simple atmosphere-slab ocean model (Wang 2010b). In the southeastern Pacific off the equator, the South Pacific subtropical dipole mode (SPSD) exhibits similar SSTA spatial structure to the SPMM or the SP SSTA footprint described in previous studies. Composite analysis of SPSD has also shown ENSO-like variability in the tropical Pacific during boreal winter following the SPSD (Zheng and Wang 2017).

The results of past studies suggest that subtropical South Pacific variability is dominated by thermodynamic coupling, while it is generally thought that dynamic interactions play a critical role in ENSO evolution (Neelin et al. 1998). However, the specific role of thermodynamic and dynamic coupling in linking the subtropical South Pacific to ENSO remains unclear because the two processes are blended in observations and in fully coupled models. In this study, we combined observational analyses and coupled model simulations to investigate the equatorial Pacific response to SPSD-like SSTA forcing. Two additional experiments were designed to separate and compare the relative roles of thermodynamic and dynamic interactions. The details of observation datasets and coupled model and model experiments are described in next section. The major evolutions of air-sea coupled variability are first briefly described from observation datasets (section 3), and then detailed processes are diagnosed from model experiments (section 4). Finally, a summary and conclusions are presented in section 5. 

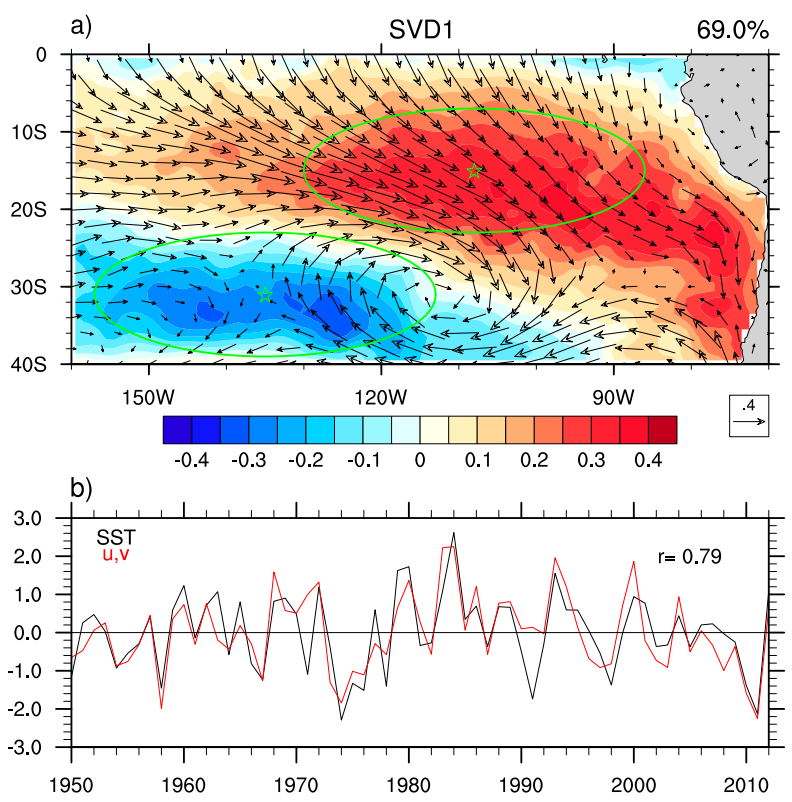

FIG. 1. (a) First singular vector decomposition (SVD) mode of SSTA (shading; ${ }^{\circ} \mathrm{C}$ ) and surface wind anomalies (vectors; $\mathrm{m} \mathrm{s}^{-1}$ ) from $\mathrm{JFM}^{1}$ of spatial patterns (correlation maps) and (b) expansion coefficients (black for SSTA and red for wind). The number at the topright corner of (a) denotes the squared covariance fraction for the leading SVD mode. The stars and ellipses in (a) indicate the centers and regions of the idealized dipolar forcing used in the model experiments. The correlation between the expansion coefficients of SSTA and wind is 0.79 . ENSO signals were removed before SVD analysis.

\section{Data and methodology}

\section{a. Observational datasets}

Observational and reanalysis datasets were used to describe the impacts of SPSD on ENSO. The Hadley Centre Sea Ice and SST dataset (HadISST), which is on a $1^{\circ} \times 1^{\circ}$ grid (Rayner et al. 2003), was analyzed for SST variability. Simple Ocean Data Assimilation (SODA), version 2.2.8 (Carton and Giese 2008), and Twentieth Century Reanalysis, version 2 (20CR; Compo et al. 2006), were used to diagnose ocean dynamic and thermodynamic processes, respectively. Sea surface height (SSH) data from SODA were used as a proxy for thermocline change, since SSH fluctuations are a good measure of thermocline depth perturbations (e.g., Rebert et al. 1985). Ocean model surface boundary conditions of SODA were provided from $20 \mathrm{CR}$, and the monthly SST and sea ice distribution used in 20CR were from HadISST. Observational analyses were based on data from 1950 to 2012, except for SODA, which is available only until 2011.

\footnotetext{
${ }^{1}$ One could get a similar SPSD pattern using monthly data (Fig. S4 in the supplemental material), and the lead-lag correlation between the SST and wind expansion coefficients peaks at lag 0 .
}

Monthly anomalies were derived relative to the climatological annual cycle over the entire period after removing the linear trend at each grid point. Since ENSO dominates interannual variability, to get the SPSD mode, ENSO influences were removed by subtracting anomalies calculated using a multiple linear regression (Wang 2010a; Zheng and Wang 2017):

$$
Y(t)=\sum_{l=1}^{L} a_{l} N_{1}(t-l)+\sum_{l=1}^{L} b_{l} N_{2}(t-l)
$$

where $N_{1}(t)$ and $N_{2}(t)$ are the principal components of the first two empirical orthogonal functions of SSTAs in the tropical Pacific $\left(12^{\circ} \mathrm{S}-12^{\circ} \mathrm{N}, 160^{\circ} \mathrm{E}-80^{\circ} \mathrm{W}\right)$, and $a$ and $b$ are regression coefficients. This procedure is applied to SST and atmospheric variables separately for each grid point in the domain concerned. As in previous studies we considered the lagged effects of ENSO on SP, where the maximum lag $L$ was set to 6 months; however, the results were not sensitive to the value of $L$ (test from 1 to 6; Zheng and Wang 2017).

\section{b. Coupled model}

The coupled model consisted of a Community Atmosphere Model, version 3.1 (CAM3.1), and a 1.5-layer reduced-gravity ocean (RGO) model. CAM3.1 is the atmosphere component of Community Climate System Model, version 3 (CCSM3), developed by the National Center for Atmospheric Research (NCAR; Collins et al. 2006a,b). The CAM3.1 has a Eulerian spectral dynamical core with spectral T42 truncation in the horizontal $\left(\sim 2.8^{\circ}\right.$ latitude by $\sim 2.8^{\circ}$ longitude grid) and 26 vertical levels.

The 1.5-layer RGO model has been successfully used to investigate tropical ocean processes and ENSO (Zebiak and Cane 1987; Clement et al. 1996). The formulation and parameters of the ocean model are described in Chang (1994). It consists of an upper layer overlaying a deep motionless layer. The upper layer is further divided into a fixed-depth surface mixed layer and a subsurface layer. The mixed layer depth is obtained from the annual mean depth estimated by Monterey and Levitus (1997). The mixed layer temperature (equivalent to the SST) depends on heat fluxes from the atmosphere, advection by surface currents, and upwelling. Surface currents include a surface Ekman component and a geostrophic component related to the gradient of the thermocline located at base of the upper layer. Upwelling is calculated by divergence of the surface currents. The temperature of entrained water beneath the mixed layer is parameterized in terms of variations in thermocline depth using a multivariate linear relationship (Fang 2005). The RGO model covers a global domain extending 


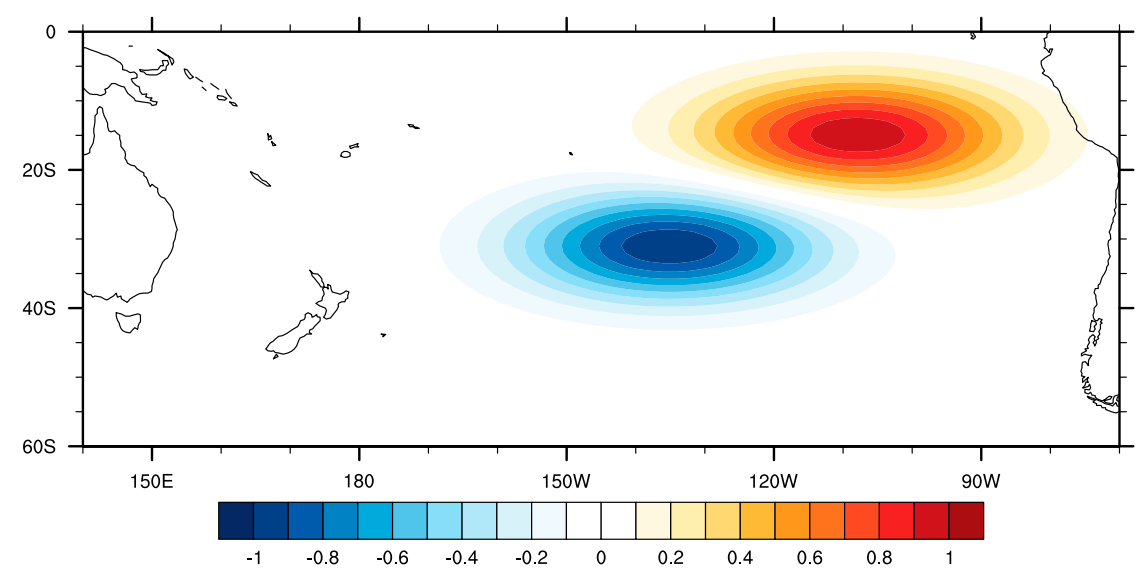

FIG. 2. Dipolar SSTA pattern added to the CAM3.1-RGO model (shading; ${ }^{\circ} \mathrm{C}$ ). The warm and cold centers are located at $15^{\circ} \mathrm{S}, 108^{\circ} \mathrm{W}$ and $31^{\circ} \mathrm{S}, 135^{\circ} \mathrm{W}$ (marked as stars in Fig. 1a), respectively.

from $80^{\circ} \mathrm{S}$ to $80^{\circ} \mathrm{N}$ with a $1^{\circ}$ latitude by $2^{\circ}$ longitude resolution; however, the thermocline outcrops at high latitudes during winter and cannot be handled in the RGO model. Where this is the case, thermocline depth was set to the mixed layer thickness. Finally, since vertical entrainment is considered less important than the surface heat flux in the heat budget of the mixed layer ocean outside the tropics, the vertical entrainment term in the thermodynamic equation of the mixed layer was ignored poleward of $30^{\circ} \mathrm{N}$ and $30^{\circ} \mathrm{S}$ (Chiang et al. 2008; Fang et al. 2008), where the model resembles a slab ocean.

The RGO model and CAM3.1 were fully coupled rather than anomalously coupled. They exchanged data once per day, at which time wind stress and surface heat fluxes were passed to the RGO model, and the RGO model transferred SST back to the atmosphere. A flux correction, which was predetermined and cycles through a 12-month climatology, was applied to the ocean to keep the SST climatology close to observation. The CAM3.1RGO model simulated the mean state in the tropics reasonably well, including thermocline depth, wind stress, and SST (Jia and $\mathrm{Wu} 2013$ ). The variability and phase locking of ENSO were also well reproduced in this model. Previous versions of this model were used to investigate the impacts of NPMM and NPO on ENSO (Chang et al. 2007; Zhang et al. 2009; Alexander et al. 2010).

\section{c. Model experiments}

Based on the SPSD spatial pattern (Fig. 1a), we defined indices (area-averaged SSTA) to represent the northern pole $\left(10^{\circ}-25^{\circ} \mathrm{S}, 90^{\circ}-125^{\circ} \mathrm{W}\right)$ and southern pole $\left(25^{\circ}-38^{\circ} \mathrm{S}\right.$, $120^{\circ}-150^{\circ} \mathrm{W}$ ) of the SPSD. Then we calculated the correlation of these indices with tropical Pacific SSTAs in the following winter (Fig. S1 in the supplemental material). The northern pole had larger correlations with tropical
Pacific SSTAs, while the southern pole was also associated with an in phase SSTA change in eastern Pacific, but with low correlations. The correlation between the January-March (JFM) SPSD index and ENSO in the following winter was reduced relative to just northern pole was included. These results suggested that the equatorward pole of the SPSD was the one critical for triggering ESNO events. However, the linear regression method used here may not fully remove the ENSO signal and may not exclude the influence of the ENSO cycle on the atmosphere-ocean system. Thus, experiments initialized with idealized forcing pattern were designed to represent the SPSD pattern and each pole of SPSD, respectively. In addition, experiments initialized with observed SPSD pattern were also performed (Fig. S2 in the supplemental material). The SST evolutions in these experiments were similar to those in idealized dipole experiments.

The pole of idealized dipolar SSTA forcing was Gaussian-shaped (Fig. 2):

$$
T=T_{0} \exp \left[-\left(\frac{\theta-\theta_{0}}{L_{\theta}}\right)^{2}\right] \exp \left[-\left(\frac{\lambda-\lambda_{0}}{L_{\lambda}}\right)^{2}\right],
$$

where $\theta$ and $\lambda$ are latitude and longitude, respectively. Here, $L_{\theta}=8^{\circ}$ and $L_{\lambda}=22^{\circ}$. For the positive pole, $T_{0}=$ $1^{\circ} \mathrm{C}, \theta_{0}=15^{\circ} \mathrm{S}$, and $\lambda_{0}=108^{\circ} \mathrm{W}$. For the negative pole, $T_{0}=-1^{\circ} \mathrm{C}, \theta_{0}=31^{\circ} \mathrm{S}$, and $\lambda_{0}=135^{\circ} \mathrm{W}$. The idealized forcing is similar to the observed SPSD pattern (Fig. 1a). We set the positive and negative poles covering the same size for easily comparing their separate contribution, although the positive pole occupied a larger region in observations. We also tested specified anomalies of SSTAs with amplitudes of $0.5^{\circ}$ and $2^{\circ} \mathrm{C}$; the results showed similar SSTA evolutions to those of the $1^{\circ} \mathrm{C}$ experiment, but the signal-to-noise ratio increased with larger-amplitude 
TABLE 1. Experiment design.

\begin{tabular}{|c|c|c|}
\hline Experiment & Model setting & SST forcing \\
\hline CTRL & Freely fully coupled. & None \\
\hline FDipole & Freely fully coupled. & Dipolar SSTA \\
\hline DDipole & $\begin{array}{l}\text { Equatorial oceans forced by a prescribed seasonal } \\
\text { cycle of surface heat flux. }\end{array}$ & Dipolar SSTA \\
\hline CTRL_Dyn & $\begin{array}{l}\text { Equatorial oceans forced by a prescribed seasonal } \\
\text { cycle of surface heat flux. }\end{array}$ & None \\
\hline TDipole & $\begin{array}{l}\text { Equatorial oceans forced by a prescribed seasonal } \\
\text { cycle of wind stress. }\end{array}$ & Dipolar SSTA \\
\hline CTRL_Therm & $\begin{array}{l}\text { Equatorial oceans forced by a prescribed seasonal } \\
\text { cycle of wind stress. }\end{array}$ & None \\
\hline SEPexp & Freely fully coupled. & Positive SSTA in the southeastern Pacific \\
\hline SCPexp & Freely fully coupled. & Negative SSTA in the south central Pacific \\
\hline
\end{tabular}

SSTA (Fig. S3 in the supplemental material). Thus, only the results of $1^{\circ} \mathrm{C}$ were analyzed in detail. The dipole forcing experiment consisted of 60 branch simulations, and ensemble averaging these simulations greatly reduced the effects of internal variability. Given that the SPSD mode peaks during JFM, each simulation was initialized with conditions on 1 March from the last 60 years of a 70-yr control (CTRL) run. A dipolar SSTA was added to the SST field (i.e., the mixed layer temperature) in the ocean model component at the initial time step and the model simulations continued to run freely until the end of the year (December; i.e., 10 months in total). The differences between these anomaly "forced" experiments and the corresponding periods from the same 1 March in the CTRL were taken as the responses. This fully coupled dipole experiments was termed FDipole.

Previous studies have shown that extratropical variations can extend to the equatorial Pacific through thermodynamic processes, but that oceanic dynamic coupling drives ENSO. To better diagnose the roles of thermodynamic and dynamic coupling near the equator, we performed two additional experiments with 30 members each. The first was a dynamically coupled dipole experiment (DDipole), which was the same as FDipole except that the equatorial oceans (within $10^{\circ} \mathrm{N}$ and $10^{\circ} \mathrm{S}$ ) were forced by a prescribed seasonal cycle of surface heat flux (derived from the CTRL) rather than by the varying atmosphere above. Between $10^{\circ}$ and $15^{\circ}$, heat flux is linearly interpolated based on seasonal cycle and atmospheric model output. In this case, thermodynamic forcing through the surface heat flux on the equatorial ocean was eliminated, while dynamic coupling through wind stress remained active (as in FDipole). Similarly, in a thermodynamic coupled dipole experiment (TDipole), wind stress was prescribed to have its climatological seasonal cycle and the surface heat flux was kept as normal values from the varying coupled atmosphere. We also performed two parallel sets of 30-member ensemble experiments, where no additional anomalies were added to the initial conditions as in the forced run (CTRL_Dyn and CTRL_ Therm in Table 1). The ensemble mean differences between the corresponding sets of experiments represent the responses to the imposed dipole SST anomalies.

Finally, two experiments forced by either the positive SSTA in the southeastern Pacific (SEPexp) or the negative SSTA in the south central Pacific (SCPexp) are performed. Each experiment had 20 branch simulations and the atmosphere and ocean were fully coupled. To avoid additional net energy input into the coupled model, the global mean SSTA was removed from the SST forcing field before being imposed into the model. All model experiments conducted here are summarized in Table 1.

\section{d. Methods}

SSTA evolution can be diagnosed in the heat balance equation:

$$
\rho C_{p} h \frac{\partial T}{\partial t}=Q_{\mathrm{net}}-\rho C_{p} h\left(\mathbf{u} \cdot \nabla T+w \frac{\partial T}{\partial z}\right)+\text { residual }
$$

where the SST tendency is balanced by the net surface airsea heat flux $Q_{\text {net }}$, horizontal and vertical advection, and a residual resulting from all other factors not explicitly calculated (e.g., mixing and diffusion). In Eq. (3), variables $T$, u, and $w$ denote temperature and the horizontal and vertical ocean current velocities, respectively; $\rho$ is seawater density, $C_{p}$ is ocean specific heat, and $h$ is the mixed layer depth. In such form, advection terms have units of watts per meter squared, which can be compared directly to the heat flux.

To further assess the effects of oceanic advection and vertical entrainment, the three-dimensional currents 
TABLE 2. Positive and negative SPSD years. Positive and negative SPSD events are defined as values of the normalized SPSD index that exceed \pm 1 . Superscripts $\mathrm{E}$ and L respectively indicate that El Niño and La Niña appear at the end of that year (ENSO years are from http://www.cpc.ncep.noaa.gov/products/analysis_monitoring/ensostuff/ensoyears.shtml).

Positive SPSD

Negative SPSD
$1960,1963,{ }^{\mathrm{E}} 1972,{ }^{\mathrm{E}} 1979,{ }^{\mathrm{E}} 1980,1983,1984,{ }^{\mathrm{L}} 1993$, and 2012

$1950,{ }^{\mathrm{L}} 1958,{ }^{\mathrm{E}} 1967,1971,{ }^{\mathrm{L}} 1974,{ }^{\mathrm{L}} 1975,{ }^{\mathrm{L}} 1976,{ }^{\mathrm{L}} 1978,1991,{ }^{\mathrm{E}} 1998,{ }^{\mathrm{L}} 2010,{ }^{\mathrm{L}}$ and $2011^{\mathrm{L}}$ and temperature were split into their mean and anomalous components, and then Eq. (3) can be rewritten as follows:

$$
\begin{array}{r}
\rho C_{p} h \frac{\partial T^{a}}{\partial t}=Q_{\mathrm{net}}^{a}-\rho C_{p} h \mathbf{u}^{m} \cdot \nabla T^{a}-\rho C_{p} h \mathbf{u}^{a} \cdot \nabla T^{m} \\
-\rho C_{p} h \mathbf{u}^{a} \cdot \nabla T^{a}-\rho C_{p} h w^{m} \frac{\partial T^{a}}{\partial z}-\rho C_{p} h w^{a} \frac{\partial T^{m}}{\partial z} \\
-\rho C_{p} h w^{a} \frac{\partial T^{a}}{\partial z}
\end{array}
$$

where superscripts $a$ and $m$ indicate the anomaly and climatological mean, respectively.

To better illustrate the WES process, we decomposed the wind speed term of LHF based on the standard bulk formula:

$$
Q_{E}=\rho_{a} L_{v} C_{E} W\left(q_{s}-q_{a}\right)
$$

where $Q_{E}$ is the surface LHF, $\rho_{a}$ is the surface air density, $L_{v}$ is the latent heat of evaporation, $C_{E}$ is the transfer coefficient, $W$ is the surface wind speed, $q_{a}$ is the surface specific humidity, and $q_{s}$ is the saturation specific humidity. Following Richter and Xie (2008), the contribution of wind speed change to LHF can be estimated as

$$
Q_{E W}=\frac{\partial Q_{E}}{\partial W}=\frac{\overline{Q_{E}}}{\bar{W}} W^{\prime},
$$

where the overline and the prime denote the time mean and departure from the mean, respectively.

\section{Influence of SPSD from observations}

We used statistical analyses to investigate the influence of SPSD on the tropical Pacific in observations. Based on the SPSD time series (Fig. 1b), typical SPSD events were selected using the criterion that values of the normalized time series should exceed \pm 1 (Table 2 ). Among these events, there were only three positive SPSD (pSPSD) events followed by an El Niño but eight negative events followed by a La Niña. Seasonal mean atmospheric and oceanic conditions were separately composited for pSPSD and negative SPSD (nSPSD) events (Figs. 3 and 4). ENSO signals were not removed when performing composites since the impact of SPSD on ENSO was the major concern.
The dipolar SSTAs of pSPSD peaked in JFM and were overlaid by lower sea level pressure anomalies (SLPAs). On the northeastern branch of the anomalous cyclone, northwesterly wind anomalies weakened the trade winds west of South America and would warm the SSTs there via $\mathrm{LHF}$ changes $\left(10^{\circ}-30^{\circ} \mathrm{S}, 100^{\circ}-140^{\circ} \mathrm{W}\right.$; LHF was defined as downward positive; Fig. 3b1). During the following season [April-June (AMJ)], warm SSTAs increased rapidly in the eastern equatorial $\mathrm{Pa}$ cific, which might be related to cross-equator northwesterly wind anomalies. The winds could deepen the equatorial thermocline and thus suppress upwelling in the eastern equatorial Pacific (Figs. 3b2,c2). Concurrently, surface currents were anomalously eastward in response to the westerly winds in the equatorial Pacific, which induces warm horizontal advection (Fig. 3d2); therefore, it was suggested that both vertical and horizontal advection contribute to warm SSTAs in the eastern equatorial Pacific. In addition, northwesterly wind anomalies and positive LHF anomalies expanded northwestward and reached the equator west of $150^{\circ} \mathrm{W}$, which slightly increased the SSTA there (Figs. 3a2,b2). This thermodynamic coupling, where the anomalous winds oppose the mean trade winds generating LHF anomalies, is similar to WES feedback in the subtropical North Pacific. These processes persisted to JulySeptember (JAS) and would lead to the development of warm SSTAs in the eastern equatorial Pacific. However, in October-December (OND), both dynamic and thermodynamic processes weakened, and the warm SSTAs in the eastern tropical Pacific decayed. The crossequator wind anomalies were weak during JAS and OND in the eastern Pacific, which reduce the thermocline depth and horizontal advection anomalies. Meanwhile, LHF anomalies should be dominated by the SSTA-induced Newtonian cooling effect as a result of the weak wind anomalies (Fig. 3b3). As a result, the negative LHF anomalies also would suppress the SSTAs west of the South American coast from JAS to OND. Therefore, the pSPSD starts to induce SST warming in the equatorial eastern Pacific, but an El Niño event did not fully develop. However, with only three members followed by El Niño in the composite, internal variability may dominate the evolution, and it might not be possible to determine the true influence of the SPSD on ENSO by observations alone. 


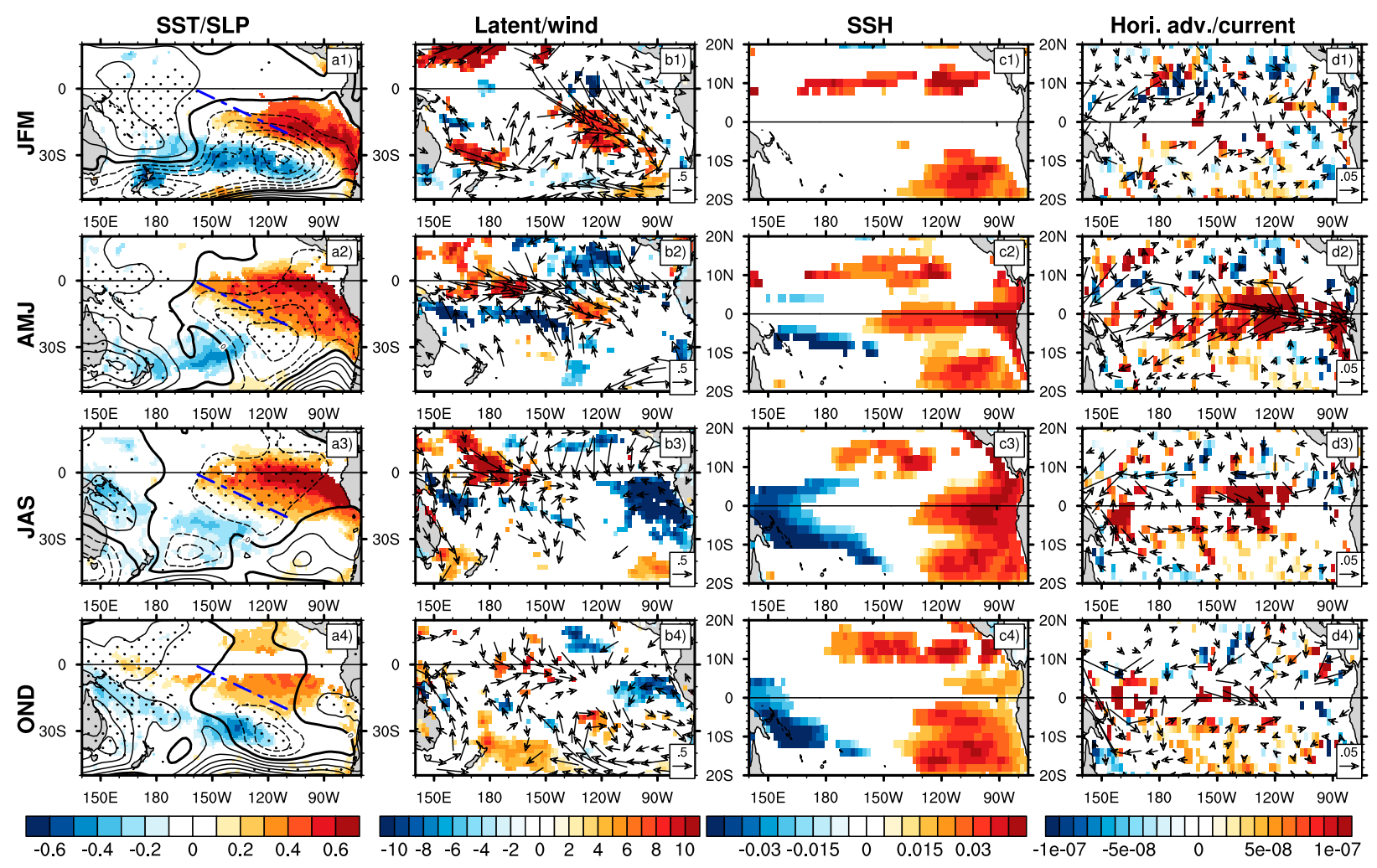

FIG. 3. Composites for positive SPSD events for (a) SSTA (shading; ${ }^{\circ} \mathrm{C}$ ) and SLPA (contours; interval (int): $0.25 \mathrm{hPa}$, thickened contours denote zero value, solid contours denote positive values, and dashed contours denote negative values) for (a1) JFM, (a2) AMJ, (a3) JAS, and (a4) OND. (b1)-(b4) As in (a1)-(a4), but for LHF (shading; $\mathrm{W} \mathrm{m}^{-2}$ ) and surface wind anomalies (vectors; $\mathrm{m} \mathrm{s}^{-1}$ ). (c1)-(c4) As in (a1)-(a4), but for SSH anomalies (m). (d1)-(d4) As in (a1)-(a4), but for oceanic horizontal advection (shading; ${ }^{\circ} \mathrm{C} \mathrm{s}{ }^{-1}$ ) and surface current anomalies (vectors; $\mathrm{cm} \mathrm{s}^{-1}$ ). Stippled regions show SLPA composites that are significant at a $90 \%$ confidence level. For the other variables, only the values exceeding a $90 \%$ confidence level are plotted.

During JFM of nSPSD, the SSTA and SLPA patterns were similar to those during pSPSD but with opposite signs (Fig. 4a1). In the southeastern Pacific, enhanced southeast winds and upward LHF anomalies are consistent with the negative SSTAs. During JAS, cold SSTAs appeared in the equatorial central Pacific, accompanied by easterly winds, lower SSH (shallower thermocline), and cold horizontal advection (Figs. 4a3-d3). The cold SSTAs continued to decrease from JAS to OND and formed a La Niña-like pattern (Fig. 4a4).

Previous studies have shown that WES feedback was responsible for propagating SSTAs from the subtropics to the equator in both the North and South Pacific (e.g., Alexander et al. 2010; Zhang et al. 2014a). To better illustrate the role of thermodynamic coupling in equatorward development of SSTAs from the eastern SP to the equator, we presented Hovmöller diagrams along a straight line from the eastern SP $\left(20^{\circ} \mathrm{S}, 110^{\circ} \mathrm{W}\right)$ to the equator $\left(0^{\circ}, 160^{\circ} \mathrm{W}\right)$. For pSPSD, the equatorward development of warm SSTAs was accompanied by lower SLPAs (Figs. 5a,b). The associated northwesterly wind anomalies also expanded to the northwest (Fig. 5b), which decelerated the wind speed and weakened the surface evaporation. The resultant downward LHF warms the ocean and further induced lower SLPAs, which are indicative of WES feedback. For nSPSD, the equatorward extensions of higher SLPAs, southeasterly wind anomalies, wind-induced LHF anomalies, and negative SSTAs could be observed from the Hovmöller diagrams (Figs. 5c,d), but they are apparent only south of $8^{\circ} \mathrm{S}$. The strong SSTAs near the equator without obvious LHF anomalies imply that dynamic processes link equatorial anomalies to the SPSD.

The observations suggest that SSTAs could be propagated from the subtropics to the equator but do not clearly show that SPSD triggered ENSO events. However, given the small sample size, especially for the positive SPSD composite, and the difficulty in separating causes and effects between ENSO and the SPSD in observations, we performed model experiments to evaluate the link between the SPSD and ENSO and to separate the role of thermodynamic and dynamic coupling in the potential linkages. 

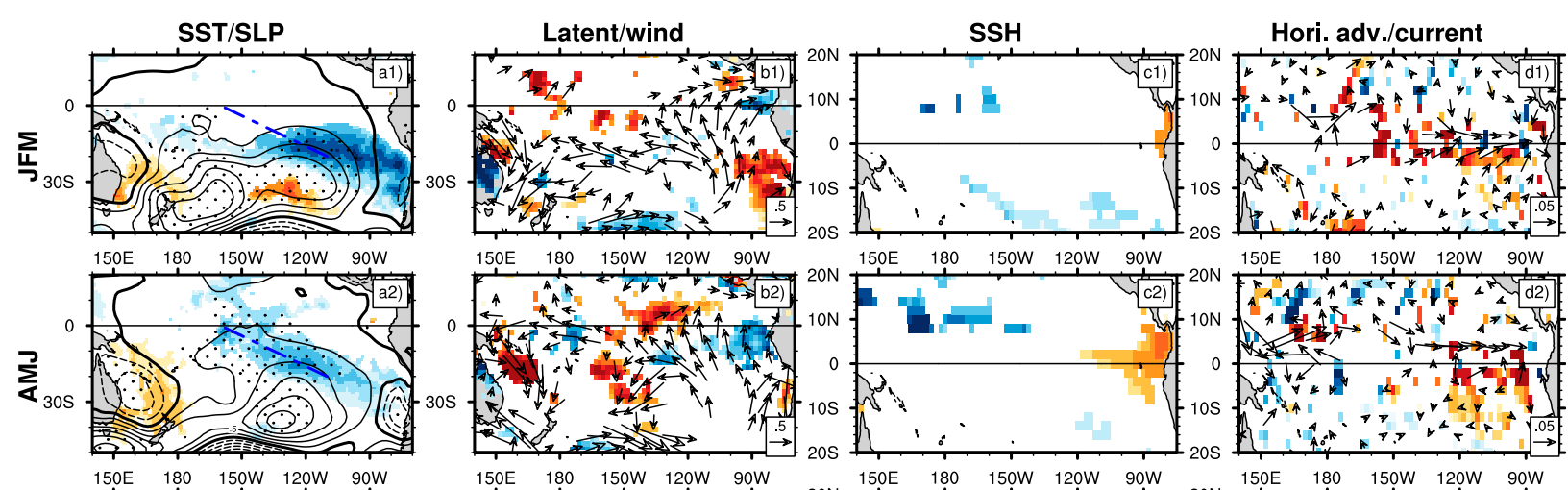

150E 180 150W 120W 90W
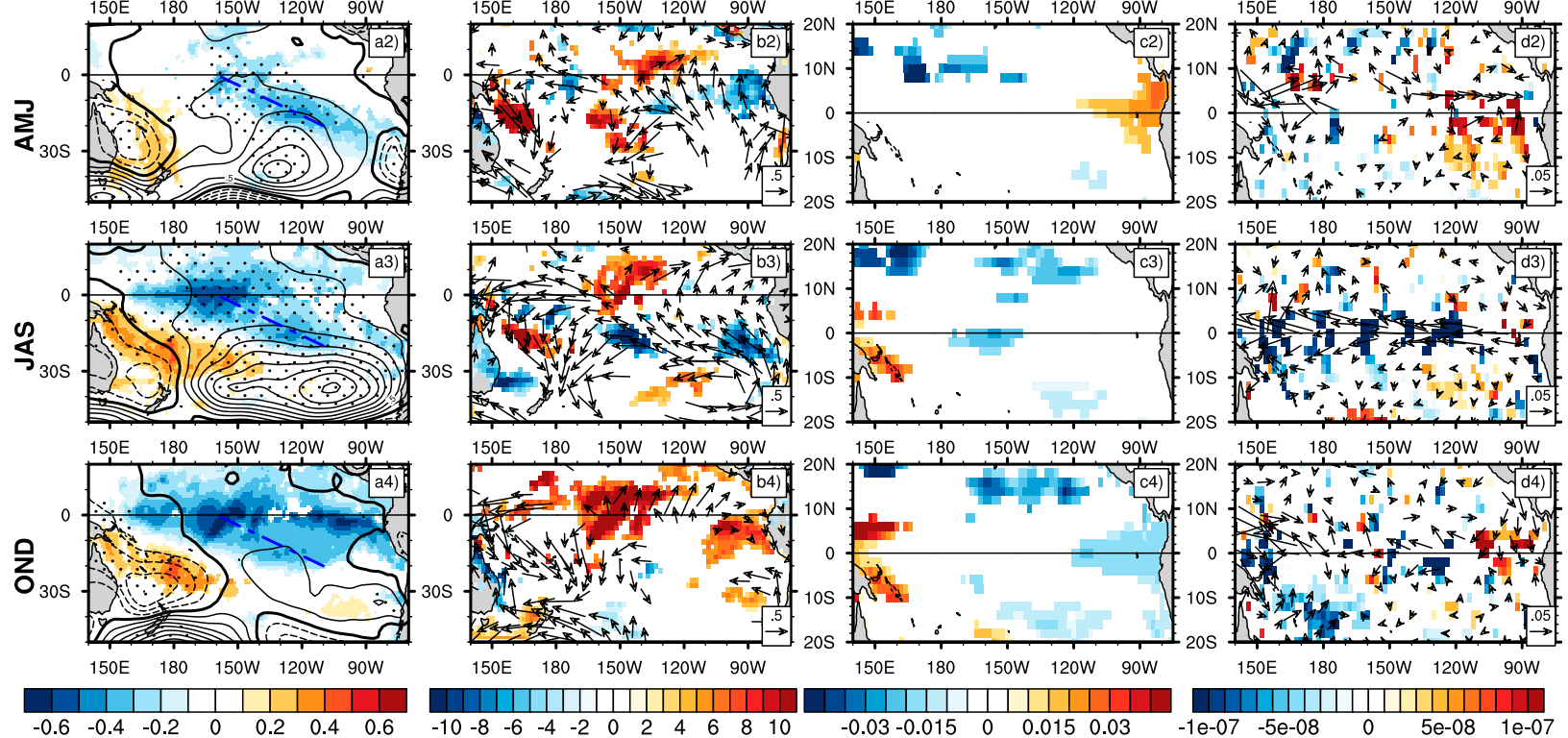

FIG. 4. As in Fig. 3, but for negative SPSD.

\section{Model responses to SPSD}

\section{a. Fully coupled model response to SPSD}

Figure 6 shows the ensemble mean differences between the FDipole and CTRL experiments. In March, the SSTA displayed the imposed dipolar anomaly (pSPSD pattern). The SLP also showed a dipole pattern, with lower (higher) pressure over warm (cold) SSTAs (Fig. 6a1). ${ }^{2}$ The center of lower SLPA was located westward relative to the warm SSTA center; therefore, there were northwesterly wind anomalies northwest of the warm SSTA (Fig. 6b1). The results indicate weakening southeast trade winds and decreased ocean LHF loss. Such a situation leads to warm SSTAs extending westward and equatorward. Propagation resulting from phase differences between wind and SST anomalies was consistent with previous analytical solutions (Wang $2010 \mathrm{~b})$ and WES feedback. Negative $\left(90^{\circ}-110^{\circ} \mathrm{W}\right)$ and

\footnotetext{
${ }^{2}$ This SLP response is the difference from the SLPA pattern in observation (Fig. 3a1). One possible reason is that observational results in Figs. 1 and 3a1 mainly represent atmospheric forcing on SSTAs. Another reason could be that the response has seasonality. The SSTA dipole and overlying SLPA pattern develop from October in observations (Zheng and Wang 2017), but the model response was set and shown in March.
}

positive $\left(120^{\circ}-150^{\circ} \mathrm{W}\right) \mathrm{LHF}$ anomalies were also found over the warm and cold SSTAs (Fig. 6b1), respectively, likely reflecting the damping of SSTAs by Newtonian cooling (Xie 1999) or a local cooling effect (Wang 2010b). At the same time, weak westerly wind anomalies in the eastern equatorial Pacific deepened the thermocline and weakened surface westward currents (Figs. 6c1,d1). The anomalous positive vertical and horizontal advection anomalies warm the eastern equatorial Pacific.

Warm SSTAs extended westward and intensified in the equatorial eastern Pacific in AMJ, with maximum values between $110^{\circ}$ and $140^{\circ} \mathrm{W}$ (Fig. 6a2). At the same time, northwest wind anomalies and downward LHF also moved northwestward. The maximum LHF was located at around $150^{\circ} \mathrm{W}$, which will help warm SSTAs to develop westward (Fig. 6b2). The developments of wind, LHF, and SST anomalies along the mean trade wind are consistent with WES feedback. Negative LHF anomalies at the equator near $120^{\circ} \mathrm{W}$ represent a Newtonian cooling response to the warmest local SSTA (Figs. 6a2,b2). Oceanic dynamic processes were also enhanced in AMJ. The thermocline clearly deepened (shallowed) on the equator westward (eastward) to about $140^{\circ} \mathrm{W}$ (Fig. 6c2). The deeper (shallower) thermocline resembled downwelling Kelvin (upwelling 

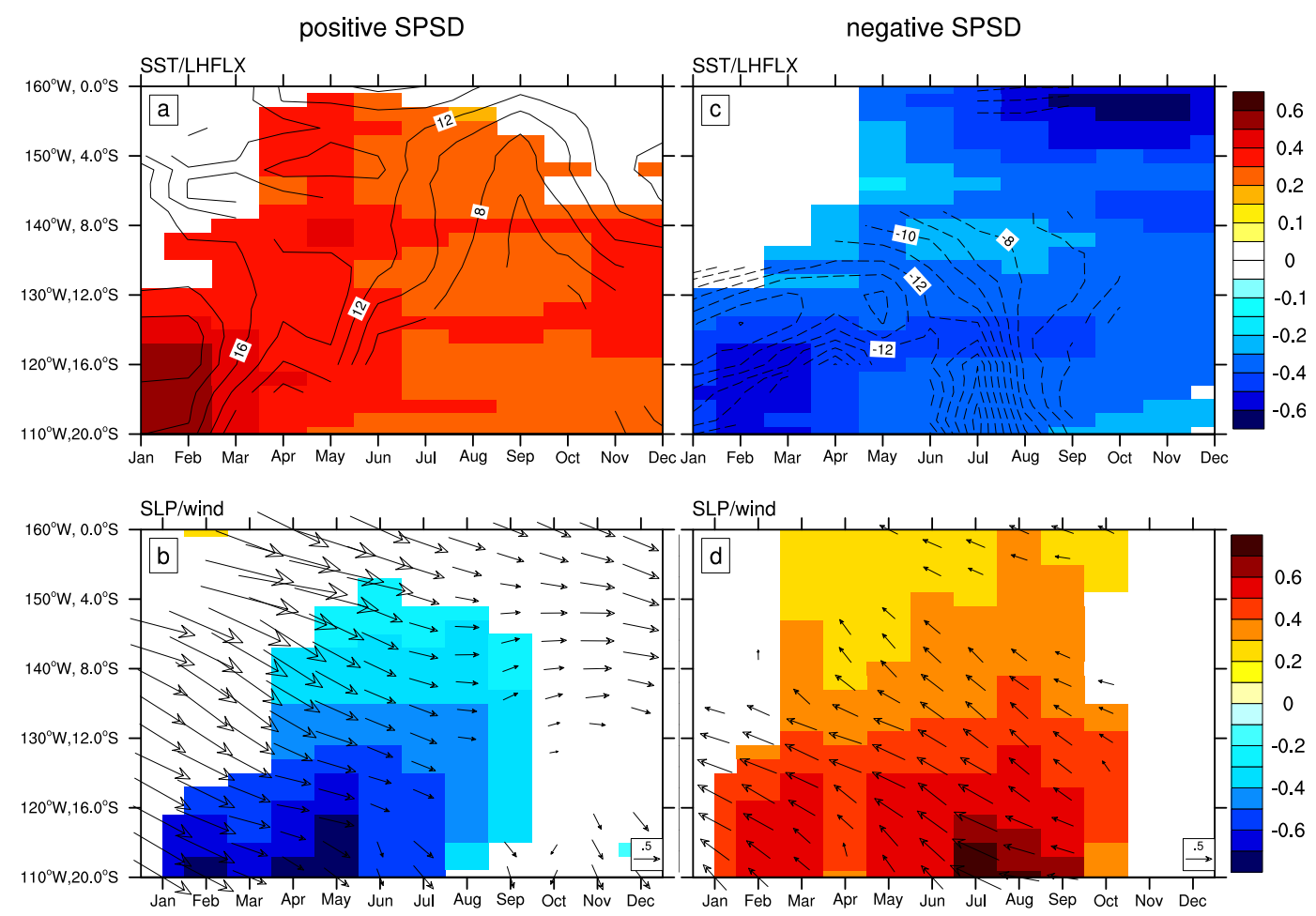

FIG. 5. Hovmöller diagrams along a straight line (dashed blue line in Figs. 3a1-a4 or 4a1-a4) labeled on the $y$ axis from the subtropical southeastern Pacific $\left(20^{\circ} \mathrm{S}, 110^{\circ} \mathrm{W}\right)$ to the central equatorial Pacific $\left(0^{\circ}, 160^{\circ} \mathrm{W}\right)$ : (a) SSTA (shading; ${ }^{\circ} \mathrm{C}$ ) and wind speed change-induced LHF anomalies (contours; int: $2 \mathrm{~W} \mathrm{~m}^{-2}$ ) [see Eq. (6)] and (b) SLP (shading; hPa) and surface wind anomalies (vectors; $\mathrm{m} \mathrm{s}^{-1}$ ) during positive SPSD events. (c),(d) As in (a),(b), but for negative SPSD events. Only the values exceeding a $90 \%$ confidence level are plotted.

Rossby) waves responding to wind curl induced by westerly wind anomalies. The strongest vertical advection anomalies were located between the positive and negative thermocline depth anomalies, which is also consistent with theoretical solutions of the tropical ocean to wind forcing (e.g., Cane et al. 1986; Neelin et al. 1998). Strong eastward surface current anomalies, appearing between the pair of thermocline Rossby waves $\left(130^{\circ}-150^{\circ} \mathrm{W}\right)$, induced horizontal advection of warm water (Fig. 6d2).

In JAS, the westerly wind and downward LHF anomalies continued to move westward (centered at $\sim 150^{\circ} \mathrm{W}$ in Fig. $6 \mathrm{~b} 2$ and $\sim 180^{\circ}$ in Fig. 6b3). Correspondingly, deeper thermocline depth anomalies extended to about $160^{\circ} \mathrm{W}$ with enlarged amplitude. Warm vertical advection nearly covered the whole central and eastern equatorial Pacific (Fig. 6c3). Both the amplitude and meridional extension of horizontal advection were enhanced and shifted westward (Fig. 6d3). The feedback among warm SSTAs, relaxed trade winds, and a deepening thermocline represented a sustained Bjerknes feedback (Bjerknes 1969). In such cases, El Niño-like SSTAs intensified both in amplitude and zonal range (Fig. 6a3). This evolution persisted to the end of the year, forming an El Niño-like SSTA pattern. Maximum anomalies were located in the central Pacific (Fig. 6a4), which is similar to El Niño in CTRL (not shown) but differs from observations, which show a maximum in the eastern Pacific (Fig. 3a3). This difference probably reflects the CAM3.1-RGO model bias (Zhang et al. 2009; Jia and Wu 2013).

To test the asymmetry in the responses to pSPSD and nSPSD in the model, we performed 40 additional simulations with nSPSD SSTA forcing (opposite sign of Fig. 2). The SST and SLP anomalies were very similar to those in FDipole (Figs. 6a1-a4) but with opposite signs (Fig. 7). For example, in both pSPSD and nSPSD runs, the maximal SSTA appeared between $120^{\circ}$ and $130^{\circ} \mathrm{W}$ in the equatorial Pacific in AMJ, and then the maximum moved to $150^{\circ} \mathrm{W}$ in JAS and the date line in OND. Thus, we mainly analyzed the model results with pSPSD forcing from here on.

The maps in Figs. 6a1-a4 suggest that warm SSTAs propagate northwestward from the eastern SP to the equator and then develop westward along the equator. To further illustrate the mechanisms of SSTA change, we plotted Hovmöller diagrams to display air-sea coupling with time. From the first Hovmöller diagram 


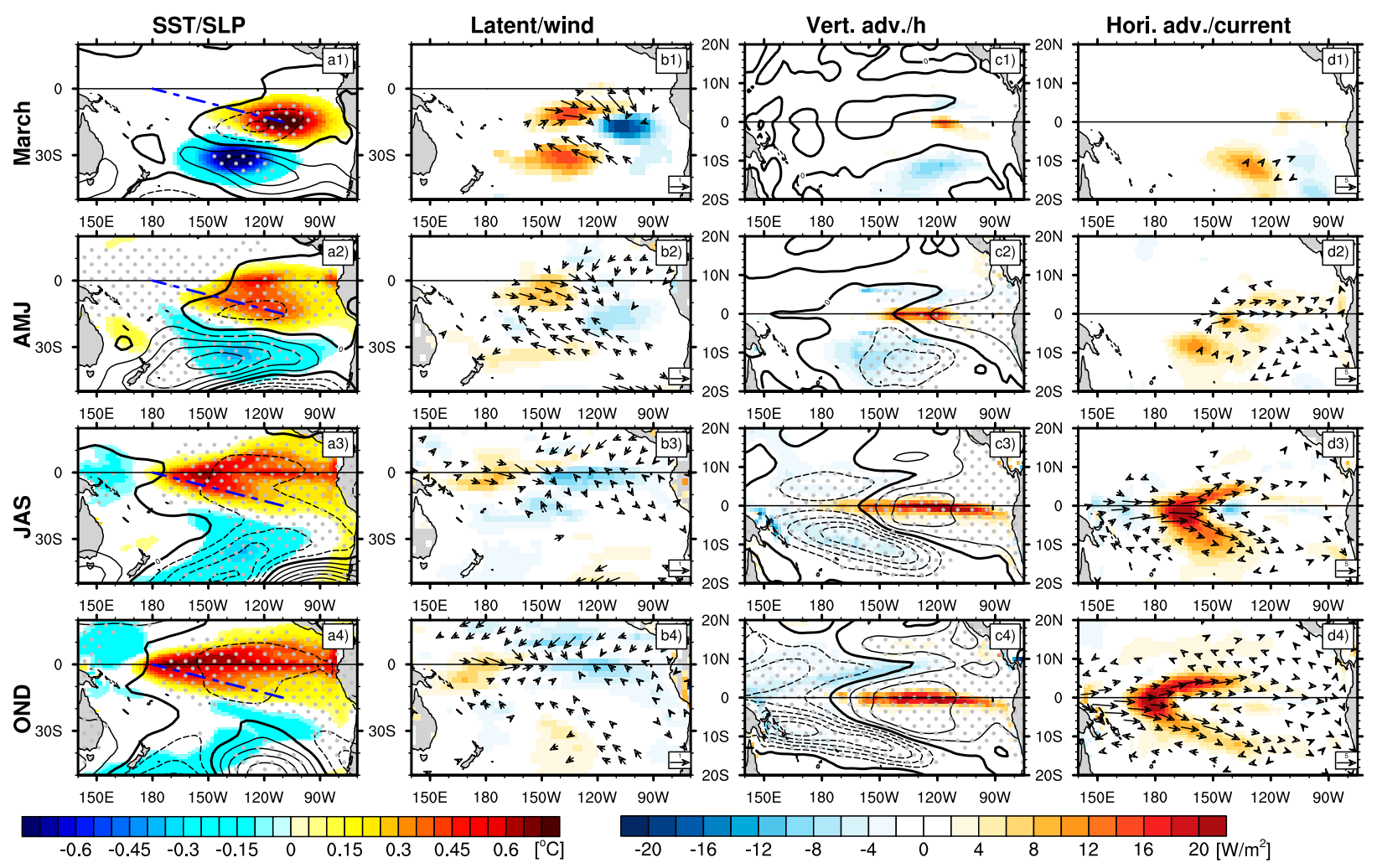

FIG. 6. Ensemble mean evolution of the response from FDipole experiment for (top)-(bottom) March, AMJ, JAS, and OND. The response is shown for (a1)-(a4) SST (shading; ${ }^{\circ} \mathrm{C}$ ) and SLP (contours; int: $0.25 \mathrm{hPa}$ ), (b1)-(b4) LHF (shading; $\mathrm{W} \mathrm{m}^{-2}$ ) and surface winds (vectors; $\mathrm{m} \mathrm{s}^{-1}$ ), (c1)-(c4) vertical advection (shading; $\mathrm{W} \mathrm{m}^{-2}$ ) and thermocline depth (contours; int: $\left.2 \mathrm{~m}\right)$, and (d1)-(d4) horizontal advection (shading; $\mathrm{W} \mathrm{m}^{-2}$ ) and surface currents (vectors; $\mathrm{cm} \mathrm{s}^{-1}$ ). Stippled regions denote SLPA and thermocline depth composites that are significant at a $90 \%$ confidence level. For the other variables, only the values exceeding a $90 \%$ confidence level are plotted. [Dashed blue lines in (a1)-(a4) indicate the path used in Fig. 8.]

(Fig. 8), which represented a straight line connecting the eastern SP $\left(15^{\circ} \mathrm{S}, 110^{\circ} \mathrm{W}\right.$; near the warm center of the imposed SSTA) to the equator $\left(0^{\circ}, 180^{\circ}\right.$; blue dashed lines in Figs. 6a1-a4), it is clear that the northwestward development of warm SSTAs is led by downward LHF (Fig. 8a). In turn, this downward LHF is caused by lower SLPAs and associated northwesterly wind anomalies that form as responses to warm SSTAs (Fig. 8b). This result clearly demonstrates the role of WES feedback in propagating SSTAs from the eastern SP into the equator, similar to the mechanism of the SPMM (Zhang et al. 2014a).

The second Hovmöller diagram shows the development of equatorial SSTAs. Warm SSTAs in the equatorial Pacific exhibited westward propagation from March to December (Fig. 9a). Positive net heat flux anomalies (which were dominated by LHF), the anomalous current $\left(-\rho C_{p} h \mathbf{u}^{a} \cdot \nabla T^{m}\right)$, and the anomalous entrainment $\left(-\rho C_{p} h w^{a} \partial T^{m} / \partial z\right)$ terms also extended westward (Figs. 9b,d,g). These processes are all related to relaxed trade winds. LHF and horizontal advection changes were basically simultaneous with SSTA tendency (Figs. 9b,d) and were responsible for the westward expansion of warm SSTAs. The anomalous vertical advection mainly contributed to the enhancement of SSTA amplitude since it lagged SSTA tendency (Fig. 9g). Warm equatorial SSTAs further induced westerly wind anomalies west of the warm SSTAs, which intensified the above three processes (see discussion about Fig. 6). In addition, the mean current term also contributed to an increase of the SSTA west of the date line starting in July (Fig. 9c). In the eastern equatorial Pacific, mean upwelling helped to maintain the warm SST (Fig. 9f), reflecting the rising subsurface temperature induced by the anomalous deeper thermocline (Figs. 6c1-c4; recalling that subsurface temperature is parameterized in terms of thermocline depth).

In summary, when initializing the CAM3.1-RGO model with an SPSD-like SSTA in March, ENSO-like SSTAs developed and matured at the end of the year in the equatorial Pacific. WES feedback works on spreading SSTAs northwestward from subtropical SP 

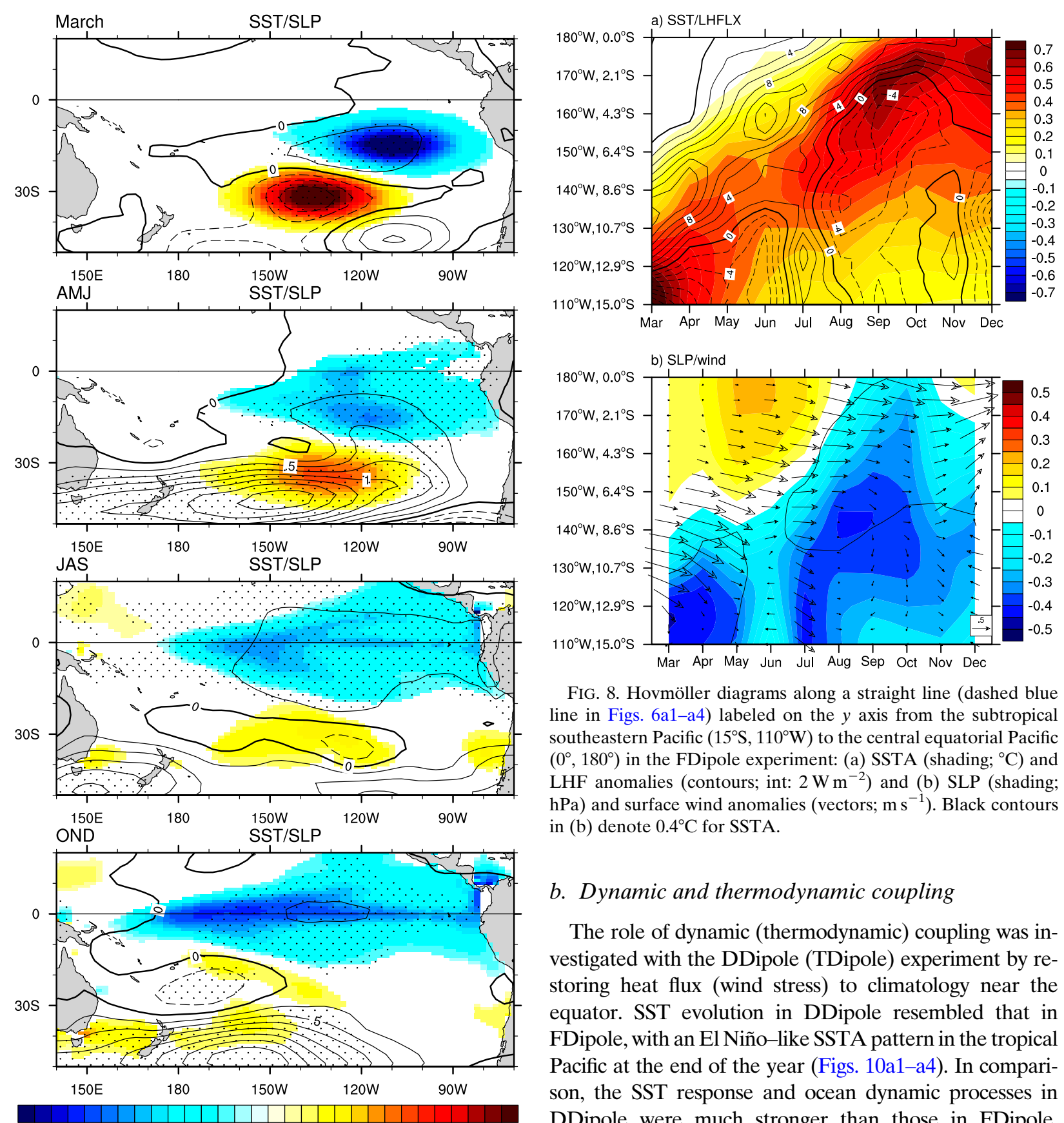

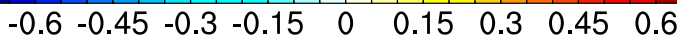

FIG. 7. SST (shading; ${ }^{\circ} \mathrm{C}$ ) and SLP (contours; int: $0.25 \mathrm{hPa}$ ) responses during (top)-(bottom) March, AMJ, JAS, and OND in the experiment with a negative phase of the SPSD (opposite sign of Fig. 2). Stippled regions denote SLPA composites that are significant at a $90 \%$ confidence level. Only SSTAs significant at a $90 \%$ confidence level are shown.

to the equator. Both thermodynamic and dynamic couplings facilitated the expansion and growth of SSTAs along the equator.

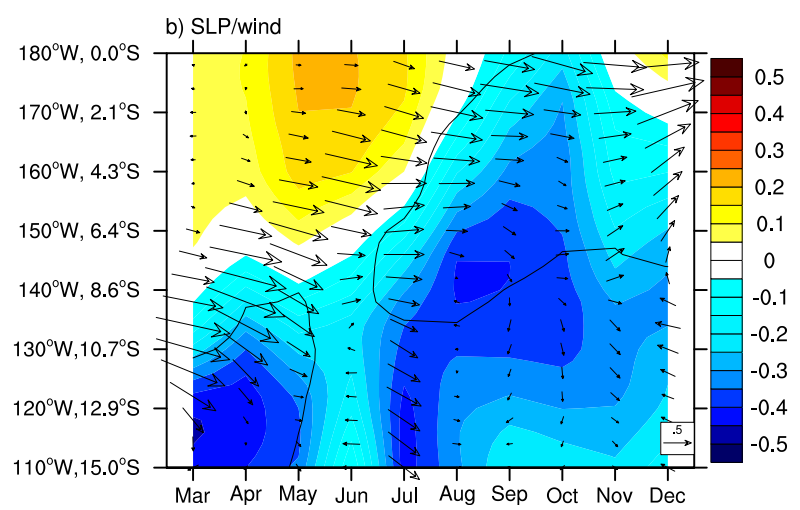

FIG. 8. Hovmöller diagrams along a straight line (dashed blue line in Figs. 6a1-a4) labeled on the $y$ axis from the subtropical southeastern Pacific $\left(15^{\circ} \mathrm{S}, 110^{\circ} \mathrm{W}\right)$ to the central equatorial Pacific $\left(0^{\circ}, 180^{\circ}\right)$ in the FDipole experiment: (a) SSTA (shading; ${ }^{\circ} \mathrm{C}$ ) and LHF anomalies (contours; int: $2 \mathrm{~W} \mathrm{~m}^{-2}$ ) and (b) SLP (shading; $\mathrm{hPa}$ ) and surface wind anomalies (vectors; $\mathrm{m} \mathrm{s}^{-1}$ ). Black contours in (b) denote $0.4^{\circ} \mathrm{C}$ for SSTA.

\section{b. Dynamic and thermodynamic coupling}

The role of dynamic (thermodynamic) coupling was investigated with the DDipole (TDipole) experiment by restoring heat flux (wind stress) to climatology near the equator. SST evolution in DDipole resembled that in FDipole, with an El Niño-like SSTA pattern in the tropical Pacific at the end of the year (Figs. 10a1-a4). In comparison, the SST response and ocean dynamic processes in DDipole were much stronger than those in FDipole, mainly reflecting the elimination of heat flux variations near the equator in DDipole, which inhibited SSTA damping by oceanic heat transfer to the atmosphere.

Similarly to FDipole and DDipole, a warm SSTA in the tropical Pacific was observed at the end of the year in TDipole simulations; however, amplitudes were much weaker and the maxima were located south of the equator (Figs. 11a1-a4). This is different from the result in FDipole or DDipole, which show maxima on the equator resulting from dynamical processes. This result is consistent with previous studies of the slab ocean 

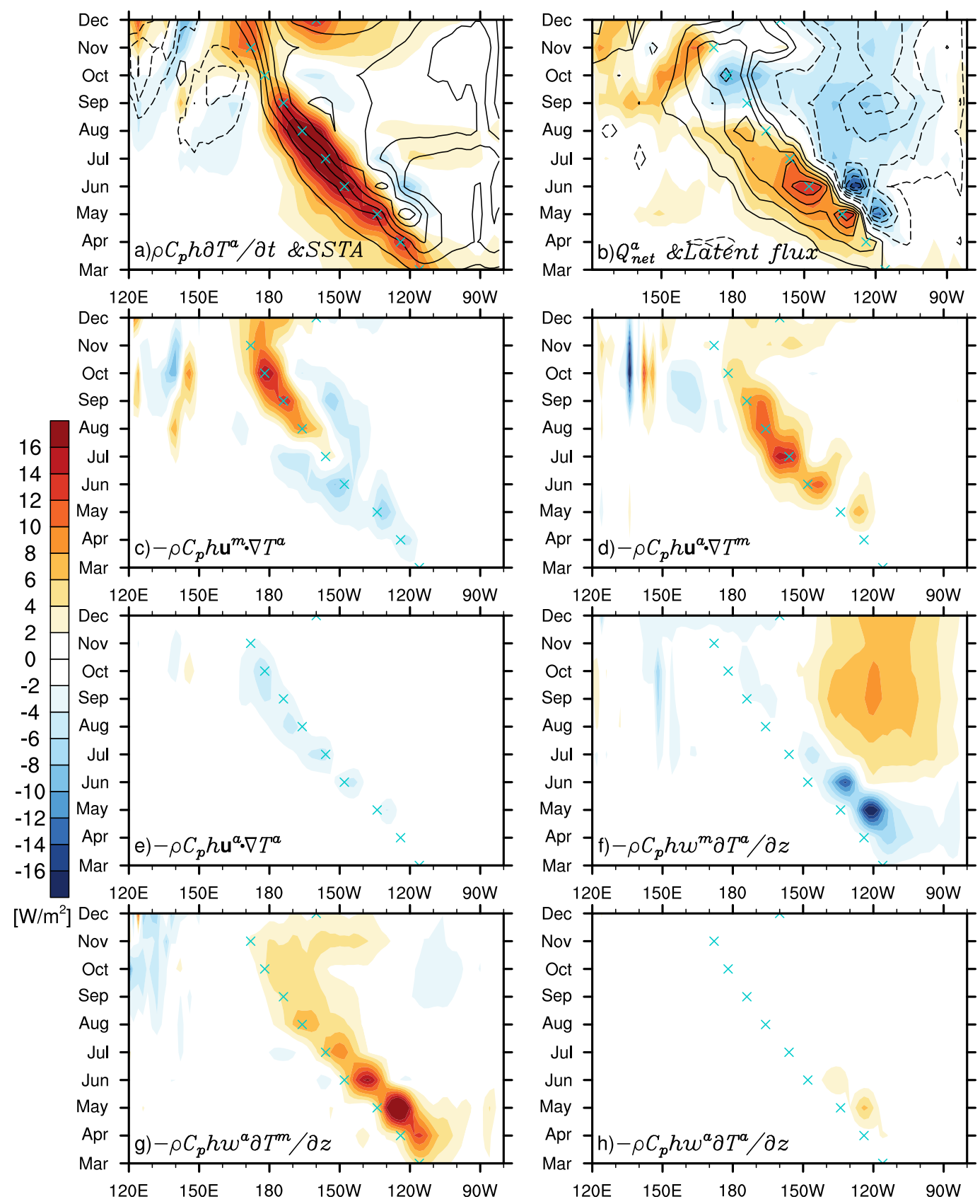

FIG. 9. Hovmöller diagrams along the equator (averaged between $5^{\circ} \mathrm{S}$ and $5^{\circ} \mathrm{N}$ ) in the FDipole experiment: (a) SST tendency (shading) and SSTA (contours; int: $0.1^{\circ} \mathrm{C}$, zero lines omitted), (b) $Q_{\text {net }}$ (shading) and LHF (contours; int: $2 \mathrm{~W} \mathrm{~m}^{-2}$, zero lines omitted), (c) mean horizontal current term, (d) anomalous horizontal current term, (e) nonlinear term of horizontal advection, (f) mean entrainment velocity term, (g) anomalous entrainment velocity term, and $(\mathrm{h})$ nonlinear term of vertical advection. Crosses in each panel indicate the locations of SST tendency maximum in each month.

model (Wang 2010b; Zhang et al. 2016), which show SSTA maxima in the subtropics rather than on the equator. In TDipole, the warmer SSTAs in the tropical eastern Pacific were observed to propagate westward via wind and LHF variations.
Hovmöller diagrams for both the DDipole and TDipole experiments are shown in Fig. 12. Similar to FDipole, the TDipole simulations include WES feedback that sustains relatively slow SSTA propagation from the subtropical southeastern Pacific to the equatorial 

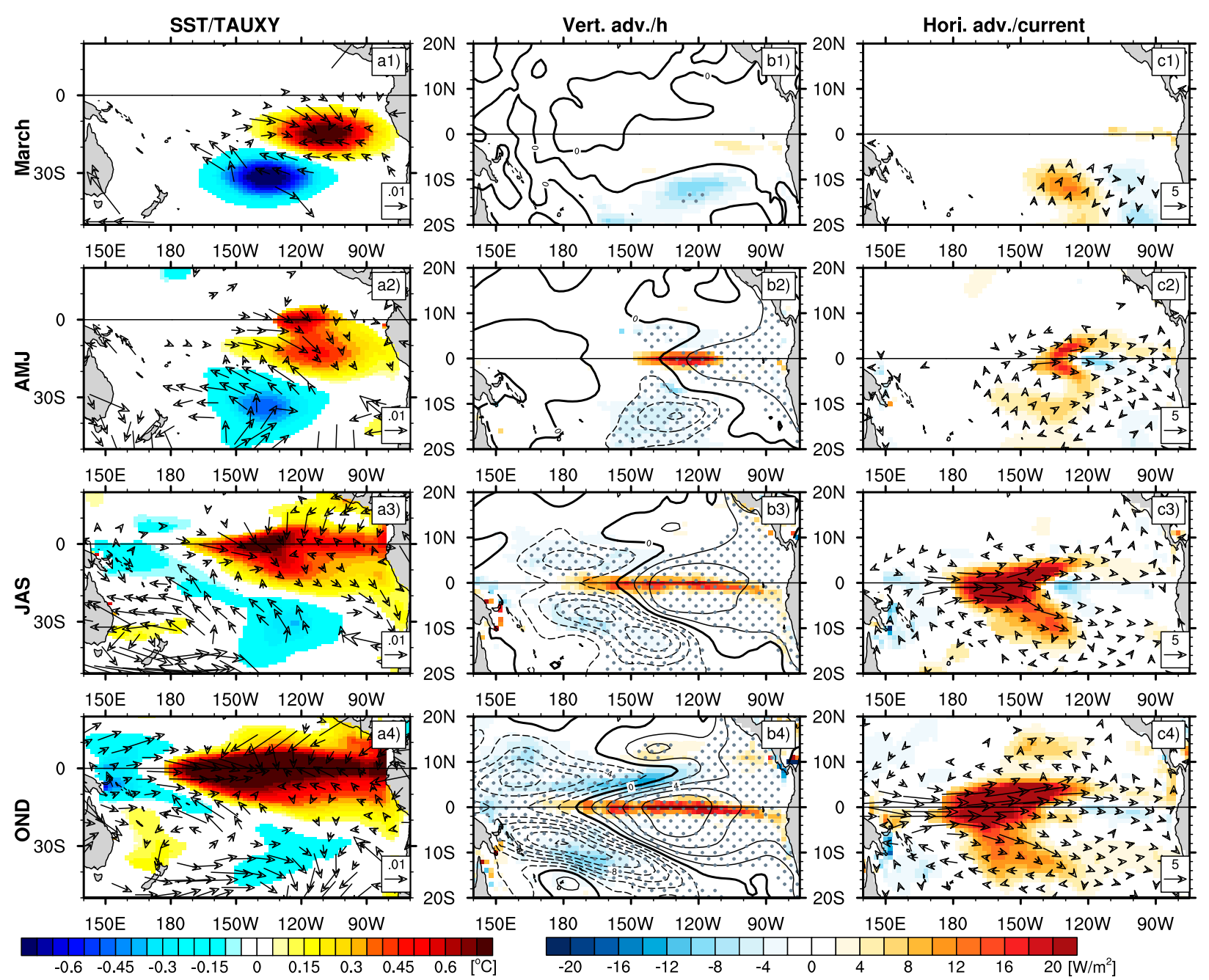

FIG. 10. As in Fig. 6, but for the DDipole experiment. The response is shown for (a1)-(a4) SST (shading) and surface wind stress (vectors; $\mathrm{N} \mathrm{m}^{-2}$ ), (b1)-(b4) vertical advection (shading; $\mathrm{W} \mathrm{m}^{-2}$ ) and thermocline depth (contours; int: $2 \mathrm{~m}$ ), and (c1)-(c4) horizontal advection (shading; $\mathrm{W} \mathrm{m}^{-2}$ ) and surface currents (vectors; $\mathrm{cm} \mathrm{s}^{-1}$ ). Stippled regions denote thermocline depth anomalies that are significant at a $90 \%$ confidence level. For the other variables, only the values exceeding a $90 \%$ confidence level are plotted.

Pacific. However, the results from DDipole runs indicate a rapid propagation of the dipole-induced signal from around $10^{\circ} \mathrm{S}$ to the equator from approximately July through September. Thus, ocean dynamical processes may also be operating in initiating ENSO events; for example, a lower pressure response to dipolar SSTA forcing could weaken cross-equator winds in the eastern equatorial Pacific (Fig. 10a1), after which westerly wind stress could warm the ocean through oceanic vertical and horizontal advection (Figs. 10b1,c1).

With regards to SST development along the equator, we found that SSTAs spread westward in both runs (Figs. 13a,c). LHF was the major contributor to westward spread in TDipole (Fig. 13b), while horizontal advection played the dominant role in DDipole (Figs. 13d,e). Both processes were apparent in the
FDipole run, leading to the fastest westward extension among the three experiments. During September, the SST tendency maxima extended to $170^{\circ} \mathrm{W}$ in FDipole, while it only reached $160^{\circ} \mathrm{W}$ in DDipole (Figs. 9a and 13c).

In summary, thermodynamic processes play a role in SSTA propagation from the subtropics to the equator and westward along the equator. However, ocean dynamical processes can induce equatorial anomalies when thermodynamic coupling is absent. Oceanic horizontal advection contributes to SSTA westward expansion along the equator. Both horizontal and vertical advection enhance SSTAs in the tropical Pacific.

\section{c. Role of each pole of SPSD}

The results of experiments with either positive SSTA in the southeastern Pacific (SEP) or negative SSTA in 

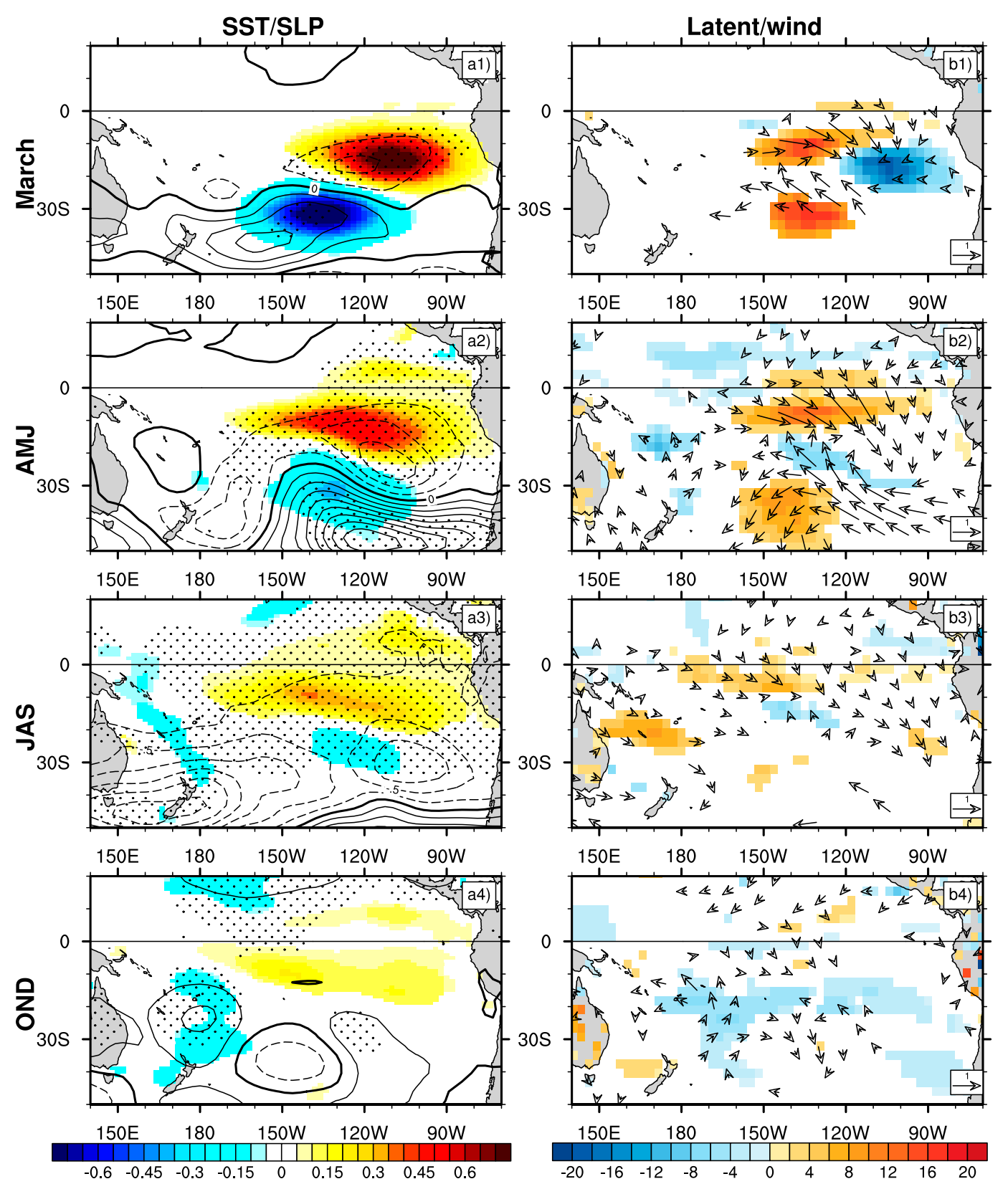

FIG. 11. As in Fig. 6, but for the TDipole experiment. The response is shown for (a1)-(a4) SST (shading; ${ }^{\circ} \mathrm{C}$ ) and SLP (contours; int: $0.25 \mathrm{hPa}$ ) and (b1)-(b4) LHF (shading; $\mathrm{W} \mathrm{m}^{-2}$ ) and surface winds (vectors; $\mathrm{m} \mathrm{s}^{-1}$ ). Stippled regions denote SLPAs that are significant at a $90 \%$ confidence level. For the other variables, only the values exceeding a $90 \%$ confidence level are plotted.

the south central Pacific (SCP) show that ENSO-like responses in SEPexp are nearly identical to those in FDipole, but with slightly stronger amplitudes (Figs. 14a1-a4). In contrast, the tropical Pacific SST response in SCPexp was found to be much weaker (Figs. 14b1-b4). In March, the cold SSTAs in SCP caused higher pressure south of $20^{\circ} \mathrm{S}$, with little signal near the equator. The cold SSTAs in SCP decayed rapidly, with only about $-0.1^{\circ} \mathrm{C}$ in
June. SST decreased in the equatorial eastern Pacific, but only reached about $-0.1^{\circ} \mathrm{C}$. After this point, the cold SSTAs continued to decay but had no further impact on the tropical Pacific. Although the two poles constitute SPSD as a thermodynamic coupling mode (Wang 2010a,b), the pole near the equator dominates the impact on ENSO, based on comparison of SEPexp and SCPexp. 

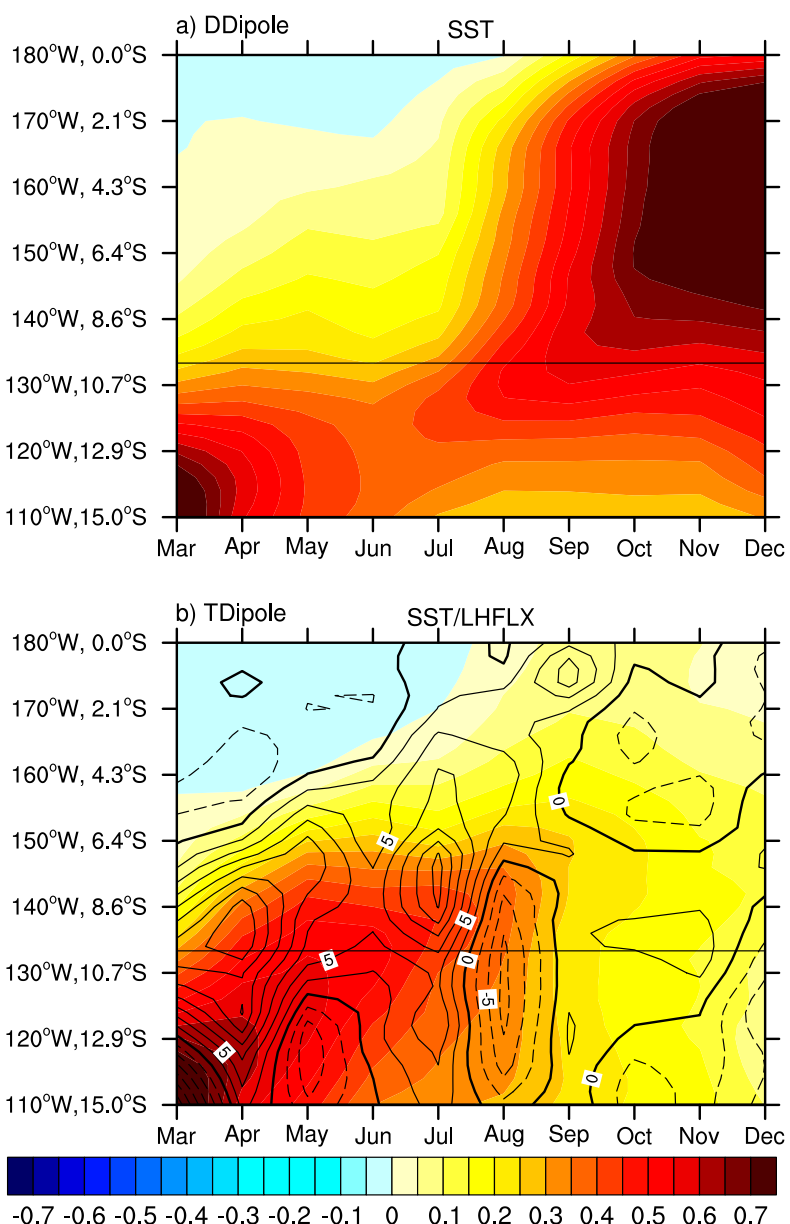

FIG. 12. As in Fig. 8, but for (a) SSTA in the DDipole experiment and (b) SSTA (shading) and LHF anomalies (contours) in the TDipole experiment. Horizontal lines indicate $10^{\circ} \mathrm{S}$.

\section{Summary and discussion}

In this study, the impact of the SPSD mode on the development of ENSO events was investigated using observational analyses and numerical coupled model experiments. First, an SPSD-like dipolar SSTA pattern (i.e., warm SSTA west of South America and cold SSTA in the central subtropical South Pacific during the positive phase) was added to the initial step of a coupled model. The results showed dipolar SSTAs coinciding with lower SLPAs south of the equator and a relaxation of climatological southeasterly trade winds northwest of the warm SSTAs, which led to a reduction in upward LHF. Consequently, thermodynamic coupling processes, namely, WES feedback, act to extend the warm SSTAs southwestward toward the equator. Reduced trade winds in the equatorial eastern Pacific also excited a downwelling equatorial Kelvin wave that deepened the thermocline, which contributed to the development of warm SSTAs and is consistent with the
Bjerknes feedback. Surface westward currents weakened under the relaxation of equatorial wind stress and produced warm horizontal advection that promoted warm SSTA growth. Through these thermodynamic and dynamic processes, warm SSTAs in the eastern Pacific were able to develop and extend westward to finally form an El Niñolike event. The model response to nSPSD was similar to pSPSD, but in observation nSPSD induced a stronger equatorial cooling than the warming induced by pSPSD.

To separate roles of dynamic and thermodynamic process, two additional experiments were performed. In the dynamic (thermodynamic) coupling run, heat flux (wind stress) was restored to climatology between $10^{\circ} \mathrm{S}$ and $10^{\circ} \mathrm{N}$. In both simulations, warm SSTAs developed in the tropical central and eastern Pacific. In the dynamic coupling run, weakened trade winds in the eastern equatorial Pacific induced by pSPSD can lead to SSTA warming through changes in horizontal and vertical advection. Positive SSTAs in the equator extend westward under oceanic horizontal advection. In the thermodynamic coupling run, warm SSTAs spread into the equator from the subtropics, after which warm SSTAs in the tropical eastern Pacific extended westward through WES feedback induced by background easterly trade winds. This mechanism was similar to the westward propagation of climatological latitudinal asymmetry in the Pacific (Xie 1996). The warm SSTA amplitude was much weaker than those in the fully coupled run and dynamic coupling run, reflecting the lack of dynamic processes. Both thermodynamic coupling and oceanic horizontal advection contribute to the westward extension of SSTAs along the equator. SSTAs spread westward fastest in the fully coupled run and slowest in the dynamic coupling run. For the dynamic coupling run, we observed rapid SSTA propagation and/ or a reformation of anomalies of SSTAs on the equator, suggesting that other processes besides WES feedback may be able to initiate ENSO events from off-equatorial SST anomalies. Additionally, while the positive and negative SPSD composites exhibited equatorward extension of wind and LHF anomalies, their effect on SSTAs was modest and did not clearly extend to the equator. Thus, WES feedback may not be necessary for propagating anomalies from the subtropical southeastern Pacific to the equator. It was suggested that NPOgenerated variations in the North Pacific trade winds could induce subsurface equatorial Pacific heat content anomalies to initiate an ENSO event (Anderson et al. 2013). This mechanism involves more than one active layer in an ocean model to represent a vertical circulation and thus is not able to be simulated by the model used here. It might contribute to link the observed SPSD to equatorial anomalies. 


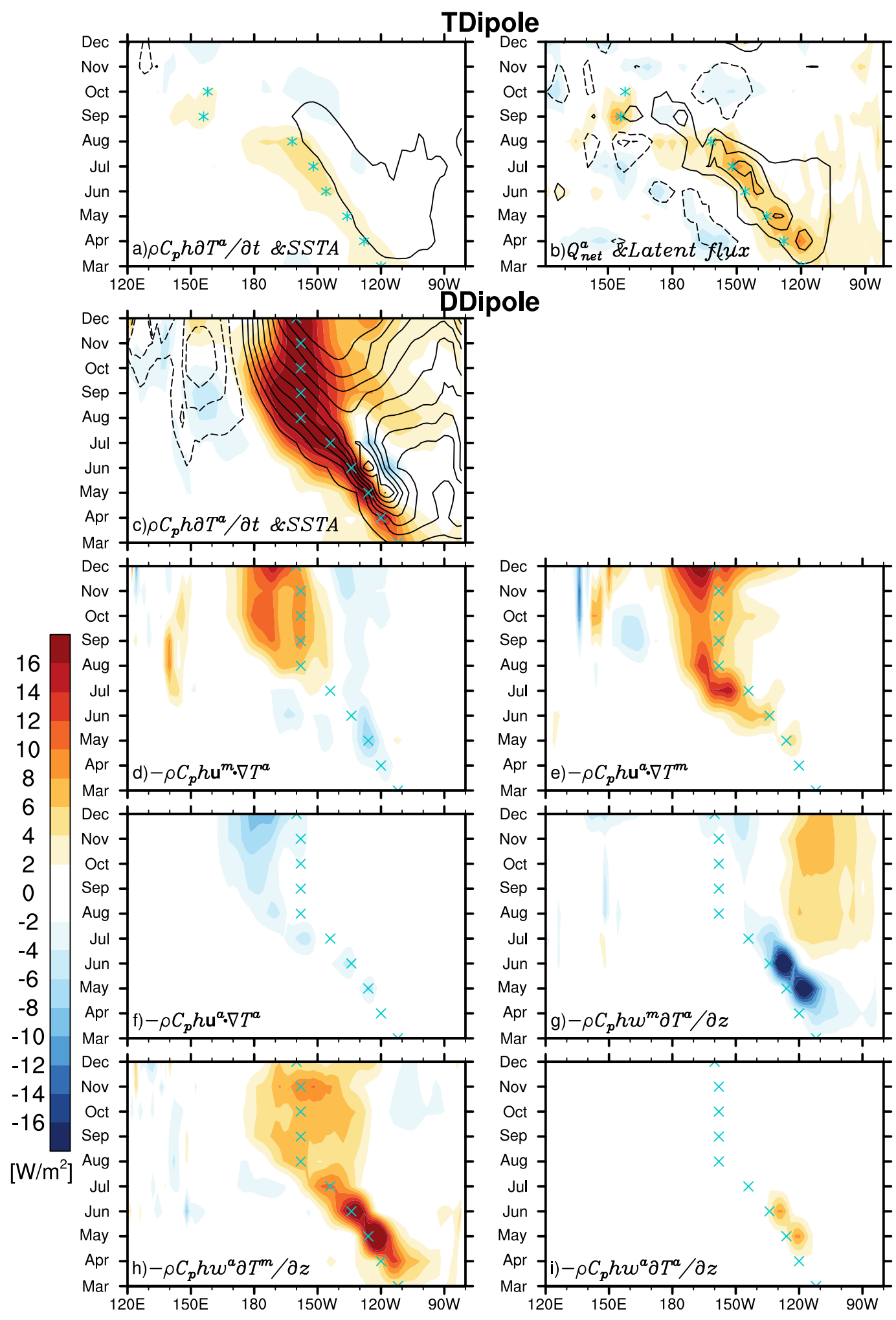

FIG. 13. Hovmöller diagrams along the equator (averaged between $5^{\circ} \mathrm{S}$ and $5^{\circ} \mathrm{N}$ ): (a) SST tendency (shading) and SSTA (contours; int: $0.1^{\circ} \mathrm{C}$, zero lines omitted) and (b) $Q_{\text {net }}$ (shading) and LHF (contours; int: $2 \mathrm{~W} \mathrm{~m}^{-2}$, zero lines omitted) in the TDipole experiment and (c) SST tendency (shading) and SSTA (contours; int: $0.1^{\circ} \mathrm{C}$, zero lines omitted), (d) mean horizontal current term, (e) anomalous horizontal current term, (f) nonlinear term of horizontal advection, (g) mean entrainment velocity term, (h) anomalous entrainment velocity term, and (i) nonlinear term of vertical advection in the DDipole experiment. Asterisks and crosses indicate the locations of SST tendency maximum in each month from TDipole and DDipole experiments, respectively. 


\section{SST/SLP}
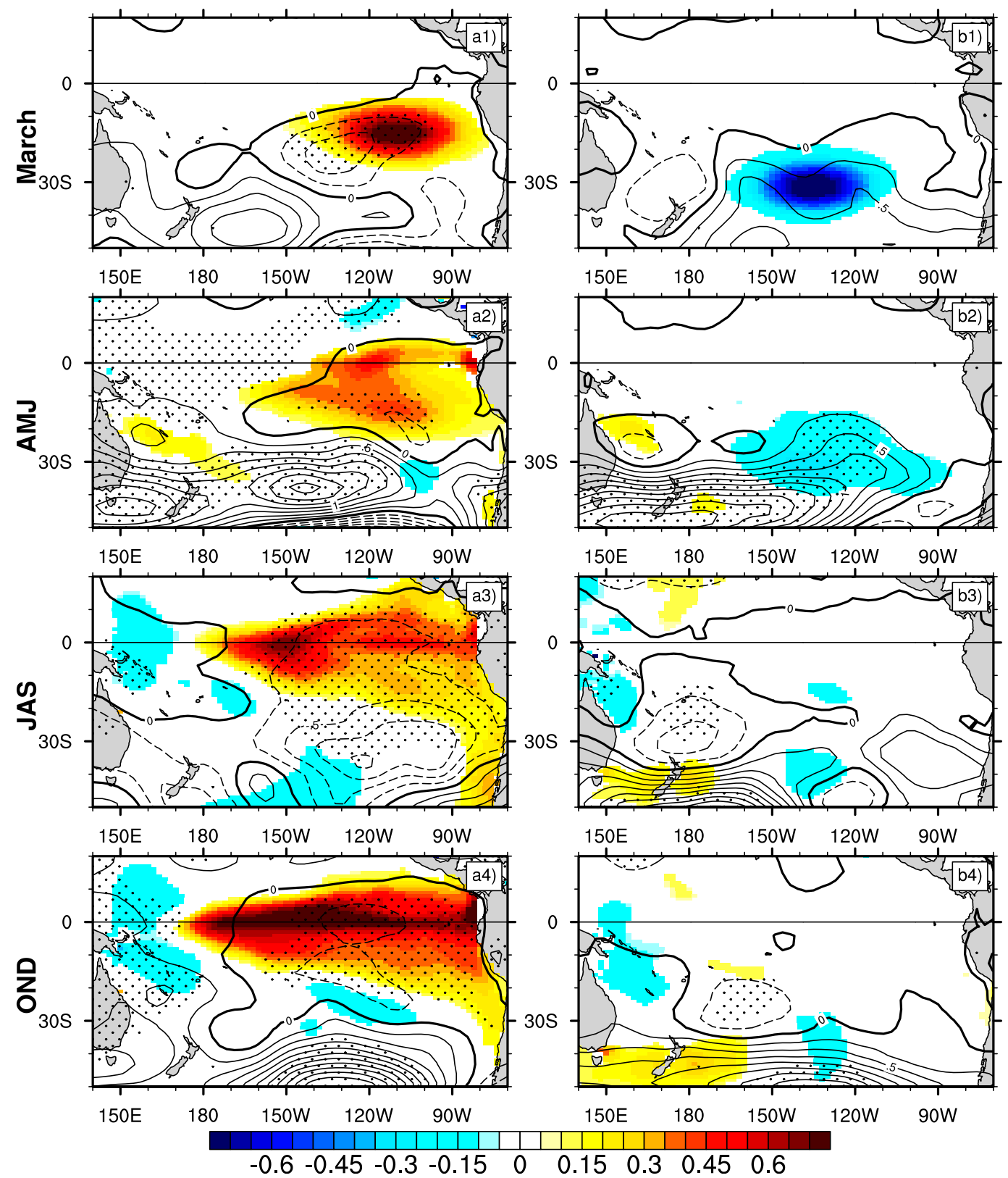

FIG. 14. As in Fig. 6, but for SST (shading; ${ }^{\circ} \mathrm{C}$ ) and SLP (contours; int: $0.25 \mathrm{hPa}$ ) responses in (a1)-(a4) SEPexp and (b1)-(b4) SCPexp. Stippled regions denote SLPAs that are significant at a 90\% confidence level. Only SSTAs significant at a $90 \%$ confidence level are plotted.

The respective contribution of each pole of SPSD was examined through two experiments. SSTAs in the lower-latitude pole played a major role in inducing ENSO-like SSTA patterns in the tropical Pacific. In contrast, SSTAs in the other pole only caused a very weak anomaly in the equatorial Pacific. The lowerlatitude pole of SPSD was similar to the SPMM of Zhang et al. (2014a); however, the difference (i.e., the physical relationship between two poles of SPSD) needs to be investigated in a future study.

There are some discrepancies between the observed composite and model experiments. In the observations, more nSPSD events were followed by a La Niña, compared to the number of pSPSD events that were followed by an El Niño. However, the model showed nearly antisymmetric responses to positive and negative 
dipole forcing. One possible reason for this difference is that there are so few cases in the pSPSD composite and the influences from other processes or other remote regions may not have been filtered out. Approximately $72 \%$ members in the experiment of $1^{\circ} \mathrm{C}$ forcing tended to simulate warmer (positive dipole forcing run) or colder (negative dipole forcing run) SSTAs in the Niño-3.4 region compared with CTRL. For the experiment of $0.5^{\circ} \mathrm{C}$ forcing, the ratio reduces to $60 \%$ and 40 ensemble members were needed to get a similar response to $1^{\circ}$ or $2^{\circ} \mathrm{C}$ forcing.

Another reason for the observation-model differences is that the model has biases. The CAM3.1-RGO model used here is a relatively simple model, especially with regards to the oceanic component. One limitation of the oceanic component is that the simulated maximal SSTA during ENSO is shifted westward compared to observations (Zhang et al. 2009). In addition, the simulated El Niño and La Niña do not show an obvious asymmetry, although the observed asymmetry is likely due in part to the very few members in the composite. One possible important flaw for this is that the temperature of entrained water is parameterized in terms of the variation of thermocline depth through a linear relationship. Both limitations should be responsible for symmetric responses to positive and negative SPSD in the model (Figs. 6a1-a4 and 7). The formulation of the oceanic component may overemphasize the contribution of thermodynamic process in the CAM3.1-RGO coupled model. The equatorward extensions of subtropical anomalies are more obvious in the simulations (Fig. 8) than those in observed composite (Fig. 5) when considering the few cases of SPSD events. In view of this, the results shown in this study, especially the comparison of dynamic and thermodynamic coupling, should be further tested in more sophisticated models, although fully coupled GCMs also displace ENSO farther west relative to observations (Capotondi et al. 2006) and have difficulty simulating the SFM (Lin et al. 2015) and the meridional mode (Amaya et al. 2017).

The influence of the subtropical North and South Pacific on ENSO shares both similarities and differences. Many studies have linked the NPMM to the equatorial central Pacific (Yu and Kim 2011; Yu et al. 2011, 2012, 2015; Kim et al. 2012; Lin et al. 2015; Vimont et al. 2014; Yeh et al. 2015), but SPSD is more likely related to SST variability in the tropical eastern Pacific (Figs. 3a1-a4). While Min et al. (2017) examined this topic using observations, the impact of extratropical processes on ENSO characteristics requires further study through the use of numerical models.

Acknowledgments. This work was supported by the Strategic Priority Research Program of the Chinese
Academy of Sciences (XDA11010102), Natural Science Foundation of China (41606018 and 41776035), Funds for Creative Research Groups of China (41421005), and NSFC-Shandong Joint Fund for Marine Science Research Centers (U1406402).

\section{REFERENCES}

Alexander, M. A., I. Bladé, M. Newman, J. R. Lanzante, N.-C. Lau, and J. D. Scott, 2002: The atmospheric bridge: The influence of ENSO teleconnections on air-sea interaction over the global oceans. J. Climate, 15, 2205-2231, https://doi.org/10.1175/ 1520-0442(2002)015<2205:TABTIO>2.0.CO;2.

- D. J. Vimont, P. Chang, and J. D. Scott, 2010: The impact of extratropical atmospheric variability on ENSO: Testing the seasonal footprinting mechanism using coupled model experiments. J. Climate, 23, 2885-2901, https://doi.org/10.1175/ 2010JCLI3205.1.

Amaya, D. J., M. J. DeFlorio, A. J. Miller, and S.-P. Xie, 2017: WES feedback and the Atlantic meridional mode: Observations and CMIP5 comparisons. Climate Dyn., 49, 1665-1679, https://doi.org/ 10.1007/s00382-016-3411-1.

Anderson, B. T., R. C. Perez, and A. Karspeck, 2013: Triggering of El Niño onset through trade wind-induced charging of the equatorial Pacific. Geophys. Res. Lett., 40, 1212-1216, https:// doi.org/10.1002/grl.50200.

Bjerknes, J., 1969: Atmospheric teleconnections from the equatorial Pacific. Mon. Wea. Rev., 97, 163-172, https://doi.org/ 10.1175/1520-0493(1969)097<0163:ATFTEP>2.3.CO;2.

Cane, M. A., S. E. Zebiak, and S. C. Dolan, 1986: Experimental forecasts of El Niño. Nature, 321, 827-832, https://doi.org/ $10.1038 / 321827 \mathrm{a} 0$.

Capotondi, A., A. Wittenberg, and S. Masina, 2006: Spatial and temporal structure of tropical Pacific interannual variability in 20th century coupled simulations. Ocean Modell., 15, 274-298, https://doi.org/10.1016/j.ocemod.2006.02.004.

Carton, J. A., and B. S. Giese, 2008: A reanalysis of ocean climate using Simple Ocean Data Assimilation (SODA). Mon. Wea. Rev., 136, 2999-3017, https://doi.org/10.1175/2007MWR1978.1.

Chang, P., 1994: A study of the seasonal cycle of sea surface temperature in the tropical Pacific Ocean using reduced gravity models. J. Geophys. Res., 99, 7725-7741, https://doi.org/ 10.1029/93JC03561.

_ L. Zhang, R. Saravanan, D. J. Vimont, J. C. H. Chiang, L. Ji, H. Seidel, and M. K. Tippett, 2007: Pacific meridional mode and El Niño-Southern Oscillation. Geophys. Res. Lett., 34, L16608, https://doi.org/10.1029/2007GL030302.

Chiang, J. C. H., and D. J. Vimont, 2004: Analogous Pacific and Atlantic meridional modes of tropical atmosphere-ocean variability. J. Climate, 17, 4143-4158, https://doi.org/10.1175/ JCLI4953.1.

—, Y. Fang, and P. Chang, 2008: Interhemispheric thermal gradient and tropical Pacific climate. Geophys. Res. Lett., 35 , L14704, https://doi.org/10.1029/2008GL034166.

Clement, A. C., R. Seager, M. A. Cane, and S. E. Zebiak, 1996: An ocean dynamical thermostat. J. Climate, 9, 2190-2196, https:// doi.org/10.1175/1520-0442(1996)009<2190:AODT>2.0.CO;2.

— P. DiNezio, and C. Deser, 2011: Rethinking the ocean's role in the Southern Oscillation. J. Climate, 24, 4056-4072, https:// doi.org/10.1175/2011JCLI3973.1.

Collins, W. D., and Coauthors, 2006a: The formulation and atmospheric simulation of the Community Atmosphere Model 
version 3 (CAM3). J. Climate, 19, 2144-2161, https://doi.org/ 10.1175/JCLI3760.1.

_ , and Coauthors, 2006b: The Community Climate System Model version 3 (CCSM3). J. Climate, 19, 2122-2143, https:// doi.org/10.1175/JCLI3761.1.

Compo, G. P., J. S. Whitaker, and P. D. Sardeshmukh, 2006: Feasibility of a 100-year reanalysis using only surface pressure data. Bull. Amer. Meteor. Soc., 87, 175-190, https://doi.org/ 10.1175/BAMS-87-2-175.

Ding, R., J. Li, and Y.-H. Tseng, 2015: The impact of South Pacific extratropical forcing on ENSO and comparisons with the North Pacific. Climate Dyn., 44, 2017-2034, https://doi.org/ 10.1007/s00382-014-2303-5.

Fang, Y., 2005: A coupled model study of the remote influence of ENSO on tropical Atlantic SST variability. Ph.D. thesis, Texas A\&M University, 93 pp.

_ J. C. H. Chiang, and P. Chang, 2008: Variation of mean sea surface temperature and modulation of El Niño-Southern Oscillation variance during the past 150 years. Geophys. Res. Lett., 35, L14709, https://doi.org/10.1029/2008GL033761.

Jia, F., and L. Wu, 2013: A study of response of the equatorial Pacific SST to doubled- $\mathrm{CO}_{2}$ forcing in the coupled CAM-1.5layer reduced-gravity ocean model. J. Phys. Oceanogr., 43, 1288-1300, https://doi.org/10.1175/JPO-D-12-0144.1.

Kim, S. T., J.-Y. Yu, A. Kumar, and H. Wang, 2012: Examination of the two types of ENSO in the NCEP CFS model and its extratropical associations. Mon. Wea. Rev., 140, 1908-1923, https:// doi.org/10.1175/MWR-D-11-00300.1.

Lin, C.-Y., J.-Y. Yu, and H.-H. Hsu, 2015: CMIP5 model simulations of the Pacific meridional mode and its connection to the two types of ENSO. Int. J. Climatol., 35, 2352-2358, https:// doi.org/10.1002/joc.4130.

Linkin, M. E., and S. Nigam, 2008: The North Pacific Oscillationwest Pacific teleconnection pattern: Mature-phase structure and winter impacts. J. Climate, 21, 1979-1997, https://doi.org/ 10.1175/2007JCLI2048.1.

Min, Q., J. Su, R. Zhang, and X. Rong, 2015: What hindered the El Niño pattern in 2014? Geophys. Res. Lett., 42, 6762-6770, https:// doi.org/10.1002/2015GL064899.

$\longrightarrow, \ldots$, and — 2017: Impact of the South and North Pacific meridional modes on the El Niño-Southern Oscillation: Observational analysis and comparison. J. Climate, 30, 1705-1720, https:// doi.org/10.1175/JCLI-D-16-0063.1.

Mo, K. C., and J. N. Paegle, 2001: The Pacific-South American modes and their downstream effects. Int. J. Climatol., 21, 1211-1229, https://doi.org/10.1002/Joc.685.

Monterey, G. I., and S. Levitus, 1997: Climatological cycle of mixed layer depth in the World Ocean. U.S. Government Printing Office, NOAA NESDIS, 5 pp.

Neelin, J. D., D. S. Battisti, A. C. Hirst, F.-F. Jin, Y. Wakata, T. Yamagata, and S. E. Zebiak, 1998: ENSO theory. J. Geophys. Res., 103, 14 261-14 290, https://doi.org/10.1029/97JC03424.

Rayner, N. A., D. E. Parker, E. B. Horton, C. K. Folland, L. V. Alexander, D. P. Rowell, E. C. Kent, and A. Kaplan, 2003: Global analyses of sea surface temperature, sea ice, and night marine air temperature since the late nineteenth century. J. Geophys. Res., 108, 4407, https://doi.org/10.1029/ 2002JD002670.

Rebert, J. P., J. R. Donguy, G. Eldin, and K. Wyrtki, 1985: Relations between sea level, thermocline depth, heat content, and dynamic height in the tropical Pacific Ocean. J. Geophys. Res., 90, 11719-11725, https://doi.org/10.1029/ JC090iC06p11719.
Richter, I., and S.-P. Xie, 2008: Muted precipitation increase in global warming simulations: A surface evaporation perspective. J. Geophys. Res., 113, D24118, https://doi.org/10.1029/ 2008JD010561.

Rogers, J. C., 1981: The North Pacific Oscillation. Int. J. Climatol., 1, 39-57, https://doi.org/10.1002/joc.3370010106.

Vimont, D. J., D. S. Battisti, and A. C. Hirst, 2001: Footprinting: A seasonal connection between the tropics and mid-latitudes. Geophys. Res. Lett., 28, 3923-3926, https://doi.org/10.1029/ 2001 GL013435.

,$- \ldots$, and,$- 2003 \mathrm{a}$ : The seasonal footprinting mechanism in the CSIRO general circulation models. J. Climate, 16, 2653-2667, https://doi.org/10.1175/1520-0442(2003)016<2653: TSFMIT $>2.0 . \mathrm{CO} ; 2$.

, J. M. Wallace, and D. S. Battisti, 2003b: The seasonal footprinting mechanism in the Pacific: Implications for ENSO. J. Climate, 16, 2668-2675, https://doi.org/10.1175/1520-0442 (2003)016<2668:TSFMIT $>2.0$. CO;2.

- M. Alexander, and A. Fontaine, 2009: Midlatitude excitation of tropical variability in the Pacific: The role of thermodynamic coupling and seasonality. J. Climate, 22, 518-534, https://doi.org/ 10.1175/2008JCLI2220.1.

, __ , and M. Newman, 2014: Optimal growth of central and East Pacific ENSO events. Geophys. Res. Lett., 41, 4027-4034, https:// doi.org/10.1002/2014GL059997.

Wang, F., 2010a: Thermodynamic coupled modes in the tropical atmosphere-ocean: An analytical solution. J. Atmos. Sci., 67, 1667-1677, https://doi.org/10.1175/2009JAS3262.1.

_ 2010b: Subtropical dipole mode in the Southern Hemisphere: A global view. Geophys. Res. Lett., 37, L10702, https://doi.org/ 10.1029/2010GL042750.

Xie, S.-P., 1996: Westward propagation of latitudinal asymmetry in a coupled ocean-atmosphere model. J. Atmos. Sci., 53, 3236-3250, https://doi.org/10.1175/1520-0469(1996)053<3236: WPOLAI $>2.0 . \mathrm{CO} ; 2$.

1999: A dynamic ocean-atmosphere model of the tropical Atlantic decadal variability. J. Climate, 12, 64-70, https://doi.org/ 10.1175/1520-0442-12.1.64

Yeh, S.-W., X. Wang, C. Wang, and B. Dewitte, 2015: On the relationship between the North Pacific climate variability and the central Pacific El Niño. J. Climate, 28, 663-677, https://doi.org/ 10.1175/JCLI-D-14-00137.1.

Yu, J.-Y., and S. T. Kim, 2011: Relationships between extratropical sea level pressure variations and the central Pacific and eastern Pacific types of ENSO. J. Climate, 24, 708-720, https://doi.org/ 10.1175/2010JCLI3688.1.

— H.-Y. Kao, T. Lee, and S. T. Kim, 2011: Subsurface ocean temperature indices for central-Pacific and eastern-Pacific types of El Niño and La Niña events. Theor. Appl. Climatol., 103, 337-344, https://doi.org/10.1007/s00704-010-0307-6.

, M.-M. Lu, and S. T. Kim, 2012: A change in the relationship between tropical central Pacific SST variability and the extratropical atmosphere around 1990. Environ. Res. Lett., 7, 034025, https://doi.org/10.1088/1748-9326/7/3/034025.

, P.-K. Kao, H. Paek, H.-H. Hsu, C.-W. Hung, M.-M. Lu, and S.-I. An, 2015: Linking emergence of the central Pacific El Niño to the Atlantic multidecadal oscillation. J. Climate, 28 , 651-662, https://doi.org/10.1175/JCLI-D-14-00347.1.

Zebiak, S. E., and M. A. Cane, 1987: A model El Niño-Southern Oscillation. Mon. Wea. Rev., 115, 2262-2278, https://doi.org/ 10.1175/1520-0493(1987)115<2262:AMENO>2.0.CO;2.

Zhang, H., A. Clement, and P. Di Nezio, 2014a: The South Pacific meridional mode: A mechanism for ENSO-like 
variability. J. Climate, 27, 769-783, https://doi.org/10.1175/ JCLI-D-13-00082.1.

C. Deser, A. Clement, and R. Tomas, 2014b: Equatorial signatures of the Pacific meridional modes: Dependence on mean climate state. Geophys. Res. Lett., 41, 568-574, https:// doi.org/10.1002/2013GL058842.

, A. Clement, and B. Medeiros, 2016: The meridional mode in an idealized aquaplanet model: Dependence on the mean state. J. Climate, 29, 2889-2905, https://doi.org/10.1175/ JCLI-D-15-0399.1.
Zhang, L., P. Chang, and L. Ji, 2009: Linking the Pacific meridional mode to ENSO: Coupled model analysis. J. Climate, 22, 34883505, https://doi.org/10.1175/2008JCLI2473.1.

Zheng, J., and F. Wang, 2017: On the formation of the South Pacific quadrupole mode. Theor. Appl. Climatol., 130, 331-344, https:// doi.org/10.1007/s00704-016-1885-8.

Zhu, J., A. Kumar, B. Huang, M. A. Balmaseda, Z.-Z. Hu, L. Marx, and J. L. Kinter III, 2016: The role of off-equatorial surface temperature anomalies in the $2014 \mathrm{El}$ Niño prediction. Sci. Rep., 6, 19677, https://doi.org/10.1038/srep19677. 